\title{
A Hidden Structural Variation in a Known IRD Gene: A Cautionary Tale of Two New Disease Candidate Genes
}

Hilary A. Scott ${ }^{1 *}$, Anna Larson ${ }^{1 *}$, Shi Song Rong ${ }^{1}$, Sudeep Mehrotra ${ }^{1}$, Rossano Butcher ${ }^{1}$, Katherine R. Chao $^{2}$, Janey L. Wiggs ${ }^{1}$, Emily M. Place ${ }^{1}$, Eric A. Pierce ${ }^{1}$, Kinga M. Bujakowska ${ }^{1}$

${ }^{1}$ Ocular Genomics Institute, Department of Ophthalmology, Massachusetts Eye and Ear, Harvard Medical School, Boston, MA.

${ }^{2}$ Center for Mendelian Genetics, Broad Institute of MIT and Harvard, Cambridge, MA.

Correspondence:

Kinga M. Bujakowska, Ph.D.

Massachusetts Eye and Ear Infirmary, Harvard Medical School

243 Charles Street, Boston, MA 02114

Phone: 617-391-5933,Email: kinga_bujakowska@meei.harvard.edu

*These authors contributed equally to this work.

Running title: Heterozygous duplication in PRPF31 causes Retinitis pigmentosa in elusive gene family 


\section{ABSTRACT}

Rod cone dystrophy ( $R C D$ ), also known as retinitis pigmentosa, is an inherited condition leading to vision loss, affecting $1 / 3500$ people. Over 270 genes are known to be implicated in the inherited retinal degenerations (IRDs), yet genetic diagnosis for $\sim 30 \%$ IRD of patients remains elusive despite advances in sequencing technologies. The goal of this study was to determine the genetic causality in a family with Rod-cone dystrophy $(R C D)$. Family members were given a full ophthalmic exam at the Retinal Service at MEE and consented to genetic testing. Whole exome sequencing (WES) was performed and variants of interest were Sanger validated. Functional assays were conducted in zebrafish along with splicing assays in relevant cell lines to determine the impact on retinal function.

WES identified variants in two potential candidate genes that segregated with disease: GNL3 (G Protein Nucleolar 3) c.1187+3A>C and c.1568-8C >A; and PDE4DIP (Phosphodiester 4D Interacting Protein) c.3868G>A (p.Glu1290Lys) and c.4603G>A (p.Ala1535Thr). Both genes were promising candidates based on their retinal involvement (development and interactions with IRD-associated proteins), however the functional assays did not validate either gene. Subsequent WES reanalysis with an updated bioinformatics pipeline and widened search parameters led to the detection of a 94bp duplication in PRPF31 (pre-mRNA Processing Factor 31) c.73_266dup (p.Asp56GlyfsTer33) as the causal variant.

Our study demonstrates the importance of thorough functional characterization of new disease candidate genes, and the value of reanalyzing NGS sequence data, which in our case led to identification of a hidden pathogenic variant in a known IRD gene. 


\section{INTRODUCTION}

Rod-cone degeneration ( $R C D$ ) also known as retinitis pigmentosa (RP) is the most prevalent type of inherited retinal disease (IRD) which causes progressive vision loss affecting $1 / 3500$ people worldwide (Haim, 2002). IRDs can be inherited as autosomal recessive, autosomal dominant, chromosome X-linked and mitochondrial traits. Genetic diagnosis may additionally be complicated due to the genetic heterogeneity of IRDs with a wide spectrum of clinical phenotypes attributed to pathogenic variants in over 270 genes (RetNet - Retinal Information Network (uth.edu). Targeted exome panels that include known IRD genes as well as whole exome sequencing are the standard approach for determining genetic diagnosis. These are largely focused on identifying single nucleotide variants (SNV), small indels and increasingly large copy number variations, allowing for the identification of causal mutations in $60 \%$ of cases (Carss et al., 2017; Consugar et al., 2014; Ellingford et al., 2018). Current gene-based therapies require accurate molecular diagnosis which provides an important incentive for determining the cause of disease in the remaining patients (Bainbridge et al., 2008; MacLaren et al., 2014; Maguire et al., 2008). A potential source of this missing causality could be found in novel candidate IRD genes. Although rare, new IRD disease genes have been discovered within the last few years for example: ARSG, CLCC1, POMGNT1, REEP6, AHR, IFT172 (Arno et al., 2016; Bujakowska et al., 2015; Khateb et al., 2018; Li et al., 2018; Xu et al., 2016; Zhou et al., 2018). Co-segregation of the variant with the ocular phenotype in large pedigrees is often the only indicator of a novel gene initially. In order to classify the variant as causal, first a gene-disease association must be established which requires further genetic and experimental investigation. Candidate genes harboring rare variants can be prioritized based on a previously characterized roles in retinal development or function, interaction of the encoded protein with known IRD-associated proteins (Audo et al., 2009; Zeitz et al., 2006; Zeitz et al., 2005), in silico pathogenicity prediction scores (Ionita-Laza et al., 2016; Jaganathan et al., 2019; Kircher et al., 2014; 
Schwarz et al., 2014; Siepel et al., 2005), and thorough validation with model organisms to characterize the impact on retinal function (Bujakowska et al., 2015).

In this study we applied the above criteria to search for novel candidate gene in a large family with three affected siblings diagnosed with RCD. Two strong candidate genes were found to cosegregate with disease. G protein nucleolar 3 (GNL3) and Phosphodiesterase 4D interacting protein (PDE4DIP) both encode proteins that are involved with retinal development or known to interact with IRD-associated proteins (Kawashima et al., 2009; Overlack et al., 2011; Paridaen et al., 2011). Possible pathogenicity of the identified variants in both genes was studied in cell and zebrafish models, however after exhaustive investigation, both candidate genes were excluded as the cause of disease. Ultimately the cause of disease was determined to be a difficult-to-detect structural variation in a known IRD gene, PRPF31 (Vithana et al., 2001). In this case, partial penetrance displayed in the unaffected mother and sibling further complicated the genetic analysis due to a misleading inheritance pattern that was actually determined to be autosomal dominant with haploinsufficiency (Abu-Safieh et al., 2006; Vithana et al., 2003). Our study demonstrates the importance of a thorough validation of new candidate genes and the value of sequence data re-analysis. 


\section{RESULTS}

A thirty-year-old female (OGI842-1649) was seen in the IRD clinic at MEE with RCD. Family history revealed that five out of seven children in the family suffered from visual impairment, with no other history of retinal degeneration in the family (Fig. 1A). Subject OGI842-1649 had decreased visual acuity, restricted visual fields and severely reduced cone responses in full-field ERG (Table 1). Her fundus images showed characteristic signs of rod-cone degeneration including peripheral bone spicule pigmentation, vessel attenuation and abnormal granularity in the macula RPE (Fig. 1B). Both parents were evaluated and showed no signs of retinal abnormalities and full-field ERGs were within normal ranges (Fig 1B, Table 1).

Molecular analysis was performed on the parents (OGI842-1653, OGI842-1831), and four siblings for whom DNA was available (OGI842-1649, OGI842-1650, OGI842-1651, and OGI842-1652). Potential causal variants obtained from exome sequencing were filtered based on minor allele frequency (MAF) $\leq 0.1 \%$. WES analysis identified rare bi-allelic variants in two candidate genes, $G$ protein nucleolar 3 (GNL3) with c.1187+3A >C and c.1568-8C >A splice region variants (Fig.2A) and Phosphodiesterase 4D interacting protein (PDE4DIP) with two missense variants (c.3868G>A, p.Glu1290Lys and c.4603G>A, p.Ala1535Thr) (Fig. 3A). Variants in both candidate genes were rare or absent in gnomAD database and were selected for further analysis based on a combination of evolutionary conservation, aberrant splicing, and pathogenicity predictions (Table 2) (Karczewski et al., 2019).

GNL3 encodes G protein nucleolar 3, also known as nucleostemin, which maintains cell proliferation and is necessary for the correct timing of cell cycle exit and differentiation (Tsai and McKay, 2002). GNL3 is expressed in retinal progenitor cells (Schmitt et al., 2009), and zebrafish gn/3 mutants were shown to have smaller eyes and delayed retinal cell development (Paridaen et al., 2011). Therefore, we hypothesized that the two splice region variants c. $1187+3 A>C$ and c. $1568-8 C>A$ in $G N L 3$ may lead to retinal dysfunction. Both changes were absent in gnomAD and TOPMed. The c.1187+3A>C 
change, located in intron 11, was predicted to affect splicing by multiple splicing prediction software, while c.1568-8C>A in intron 14 had an elevated Eigen score (Ionita-Laza et al., 2016), and both were predicted to be disease causing by Mutation Taster (Table 2)(Schwarz et al., 2014). Both variants were studied by splicing assays in HEK293T cells. The splicing constructs spanned exons surrounding the studied variants with two controls: a wild type and an essential splice site control (Fig. 2 B, C). Next generation sequencing (NGS) analysis of the midi-gene transcripts revealed skipping of exon 11 and 12 in the c.1187+3A>C variant and essential splice site control (Fig. 2B). However, the second studied variant, c.1568-8C >A, had no effect on splicing (Fig. 2C). This variant was therefore considered to be nonpathogenic. In addition, knocking down gn/3 with a splice blocking morpholino oligonucleotide (MO) in zebrafish did not show any morphological or functional effects on the eye or the retina (Supplementary material Fig. S1). These findings conclusively dismissed GNL3 as being the cause of disease in this family.

We therefore turned our attention towards the second candidate gene, PDE4DIP whose product, myomegalin, is involved in cAMP-dependent signaling (Verde et al., 2001) and organization of centrosomal and Golgi-derived microtubules (Wang et al., 2014). Isoforms of myomegalin in the retina have been shown to interact with Sans, encoded by USH1G, Usher syndrome 1G (Overlack et al., 2011). Loss of USH1G causes congenital hearing loss and RCD (Mustapha et al., 2002) thus the implication of PDE4DIP playing a role in the Usher interactome made it a promising candidate gene for retinal degeneration (Weil et al., 2003). WES detected two missense variants in PDE4DIP (c.3868G>A, p.Glu1290Lys and c.4603G>A, p.Ala1535Thr; NM_001198834.3) that are rare in gnomAD and are highly conserved (Karczewski et al., 2019) (Fig. 3A-B, Table 2).

Zebrafish studies were carried out to determine the effect of pde4dip MO knock-down on the retina (Fig.3C-D). Even though no structural retinal abnormalities were observed (Fig. 3E), pde4dip morphants showed reduced function in the visual motor response (VMR) (Fig. 3D). To exclude the 
possibility that the reduced VMR response was a result of other developmental anomalies rather than retinal malfunction, we performed an acoustically evoked behavioral response (AEBR) assay. AEBR measures the motor response after an acoustic stimulus, providing a vision independent control. In the AEBR experiment, pde4dip morphants had lowered startle response compared to control fish indicating other developmental defects unrelated to vision was affecting motor response (Fig.3E). Upon a closer inspection of the fish morphology, we realized that $~ 50 \%$ of the pde4dip morphants showed maldeveloped gas bladders, which indicates a general swimming impediment and explains reduced or lack of startle response upon visual or acoustic stimulation (Fig. 3F). Similar experiments repeated in CRISPR/Cas9 generated pde4dip mutant larvae also showed no retinal phenotype. (Supplementary Fig. S4). Given this, we concluded that the pde4dip morphant phenotype is not specifically related to vision and that the loss of pde4dip in zebrafish and likely other organisms has no effect on retinal development and is unlikely the cause of disease in the studied family.

As both candidate genes were disproven, WES data was reanalyzed. Removing the inheritance and variant quality filters (variant quality score recalibration) (McKenna et al., 2010a) led to the identification of a 94 nucleotide tandem duplication within the first coding exon of Pre-mRNA Processing Factor 31, PRPF31, which is expressed in all tissues, including the retina, (Lonsdale et al., 2013) https://www.gtexportal.org/home/gene/PRPF31). The PRPF31 encoded protein, U4/U6 small nuclear ribonucleoprotein Prp31, facilitates protein-RNA interactions required for spliceosome assembly. The retina may be particularly sensitive to perturbations in splicing as mutations in splicing factors (Tanackovic et al., 2011), including SNRNP200, PRPF3, PRPF8, and PRPF31 among others, are known to cause autosomal dominant rod-cone dystrophy (Chakarova et al., 2002; McKie et al., 2001; Vithana et al., 2001; Zhao et al., 2009). The duplication, c.73_166dup, leads to a frameshift that creates a stop codon, p.Asp56GlyfsTer33 (Fig.4A) most likely resulting in nonsense mediated decay of the transcript (Fig. 4B). PCR amplification of the region surrounding the duplication confirmed that all three affected 
family members (OGI842-1649, OGI842-1650, OGI842-1651) carry this variant, as well as the unaffected sibling (OGI842-1652) and the mother (OGI842-1831), indicating incomplete penetrance (Fig.4C). Sanger sequencing confirmed mapping of the duplication to hg19: chr19:54,621,731-54,621,824

(Fig.4D). The disease mechanism of PRPF31 is known to be haploinsufficiency and therefore the uncovered heterozygous loss-of-function variant was determined to be the cause of disease in this family, with two asymptomatic mutation carriers. Partial penetrance, a known feature of PRPF31associated RCD (Rivolta et al., 2006; Vithana et al., 2003), explains the initial assumption that disease inheritance in this pedigree was autosomal recessive. The inheritance of the wild type allele was shown to determine disease penetrance (Rivolta et al., 2006; Vithana et al., 2003), which was also seen in the presented family, where the unaffected sibling inherited a different wild type allele from her father than the affected siblings (Fig. 4A). 


\section{DISCUSSION}

Our study describes a search for the genetic cause of disease in an RCD family whose inheritance pattern appeared to be autosomal recessive with three affected members. Whole exome sequencing identified rare variants in two candidate genes that segregated with the disease phenotype and met the criteria determined in the outset of the study being highly conserved, rare or absent in genome aggregation databases, predicted to be disease causing and having relevant interactions with known IRD genes. The first candidate gene investigated GNL3, also known as nucleostemin, belongs to a family of Nucleolar GTP-binding proteins which includes members GNL3L and GNL2 which has been shown to be expressed in retinal precursors (Kawashima et al., 2009; Schmitt et al., 2009). Zebrafish models show both that $\mathrm{gn} / 2^{--}$and $\mathrm{gn} / 3^{--}$play a role in retinal neurogenesis with their loss leading to delayed retinal differentiation. Proteins coded by these genes have partly redundant function with $\mathrm{gn} / \mathrm{3}^{-\%}$ displaying a milder phenotype with transient abnormalities at early stages of development at 22 hours post fertilization (hpf), which resolve at later time points (Paridaen et al., 2011). However, our results showed no phenotype associated with knock down of gn/3 using a splice blocking morpholino. Our attempts to employ a translational blocking morpholino that would have arguably been a stronger knock down and more closely comparable to the previous knock out model, resulted in a "monster" phenotype and therefore could not be studied further. The lack of developmental phenotype in our gn/3 morphants may also be due to the fact that we evaluated the morphant larvae at a later developmental stage, at $5 \mathrm{dpf}$ rather than $22 \mathrm{hpf}$ (Paridaen et al., 2011). Ultimately, the lack of phenotype in our zebrafish knockdown, as well as the absence of splicing aberrations in in vitro assays, led us to exclude GNL3 as the cause of disease in this family. The second gene, PDE4DIP, encodes myomegalin, which has been shown to interact with SANS, an Usher interactome protein encoded by USH1G (Overlack et al., 2011). In the end, functional assays in zebrafish failed to demonstrate PDE4DIP impacted retinal function. Our results thus demonstrate the importance of not only the stringent selection criteria for candidate genes 
but also of rigorous functional validation to avoid falsely reporting new disease genes. Even though most of the new disease gene associations demonstrate multiple levels of evidence for the pathogenicity of discovered variants, a recent study by Hanany and colleagues demonstrated a high false discovery rate within autosomal dominant IRD genes that was a result of mistakenly classified pathogenic variants (Hanany and Sharon, 2019). In our case, both genes appeared to be strong candidates and only functional analyses led to the exclusion of both candidate genes as the cause of disease.

Re-analysis of sequencing data led to the detection of a causative $94 \mathrm{bp}$ tandem duplication (NM_015629.4:c.73_166dup (p.Asp56fs) which creates a premature termination codon in PRPF31. The duplication was present in the unaffected mother and an unaffected sibling. The mother displayed no clinical manifestations of RCD even though she carried the mutation. The unaffected sibling was not studied clinically, however reported no symptoms. Additionally, she inherited an alternate wild type allele compared to her affected sibs further supporting partial penetrance that obscured the autosomal dominant inheritance pattern. In addition, the 94bp duplication is too large to be included in the standard high quality alignments and too small to be detected by read-depth CNV detection algorithms, such as gCNV (McKenna et al., 2010b). This led to the PRPF31 variant being excluded in the initial variant filtering, even though loss of function variants in PRPF31 are a known cause of dominant RCD through haploinsufficiency (Abu-Safieh et al., 2006). Structural changes have increasingly been shown to contribute to retinal disease, with an estimated contribution of CNVs of up to $9 \%$ of IRD cases (Ellingford et al., 2018; Van Cauwenbergh et al., 2017; Zampaglione et al., 2020). Gene size has been shown to be the strongest predictor for genes enriched with structural variation followed by long interspersed nuclear elements (LINE), long terminal repeats (LTR), and segmental duplications (Van Schil et al., 2018). For example, USH2A is one of the largest IRD genes $(800.5 \mathrm{~kb}$, hg19 chr1:215,796,236$216,596,738)$ and a recent publication found potentially causal structural variants in $9 \%$ of an Usher 
syndrome cohort (Bonnet et al., 2016b). PRPF31, however is an outlier. It is a small gene (16.3 kb, hg19 chr19:54,621,731-54,621,824) that is not in proximity to regions prone to non-homologous allelic recombination (NAHR)(Bujakowska et al., 2016), yet likely causal CNVs account for a large number of patients with PRPF31-associated disease (Sullivan et al., 2006; Zampaglione et al., 2020). PRPF31 does contain a large number of total repeats relative to its size including low copy repeats that flank unique sequences which lead to non-recurrent CNVs (Carvalho and Lupski, 2016), as well as LINE and LTR (Van Schil et al., 2018). In the present case, the location of the duplication is in a low complexity region containing simple repeats, and the flanking sequences of the duplication contains a repeat (GCTATGGG) that may have facilitated DNA polymerase errors leading to the inclusion of the intervening region (Fig.4D). The enrichment of genomic rearrangements combined with the complex inheritance pattern likely contributes to the underreporting of causal variants in PRPF31. Recent studies have shown diagnostic rates are improved by applying CNV analysis in an unbiased way in the initial analysis along with standard NGS pipelines, and this would allow for detection of causal CNVs in autosomal dominant genes such as PRPF31 (Bonnet et al., 2016a; Ellingford et al., 2018). The overall contribution of PRPF31 mutations in IRD is likely underestimated and should be considered in apparent autosomal recessive pedigrees without a clear solution in a known IRD gene.

This case study highlights the importance of thorough functional characterization of new candidate genes and the value of reanalysis of NGS sequence data as false discovery of novel genes can obscure true genetic diagnosis and may prevent the use of appropriate gene-based therapies in affected patients. 


\section{METHODS}

\section{Ethical guidelines}

The study was approved by the institutional review board at the Massachusetts Eye and Ear (MEE), an affiliate of Mass General Brigham (MGB) healthcare system (Human Studies Committee MGB, Boston, MA, USA) and complied with the Health Information Portability and Accessibility Act (HIPAA). All aspects of the project adhered to the tenets of the Declaration of Helsinki. Informed consent was obtained from all individuals on whom genetic testing and further molecular evaluations were performed.

\section{Clinical evaluation}

Ophthalmic evaluations were performed by clinicians experienced in inherited retinal degenerations at MEE. Visual acuity was measured using Snellen and Early Treatment of Diabetic Retinopathy Study (ETDRS) charts. Kinetic perimetry was performed using a Goldmann perimeter. Full-field electroretinograms (ERG) were performed using Burian Allen electrodes and custom ERG system with previously described parameters (Marmor et al., 2009; Reichel et al., 1989).

\section{Genetic screening}

DNA extracted from venous blood using the DNeasy Blood and Tissue Kit (Qiagen, Hilden, Germany) was used for all the sequencing reactions. Whole exome sequencing (WES) was performed on OGI842-1649, OGI842-1651, OGI842-1653, OGI842-1831 and data processing were performed by the Genomics Platform at the Broad Institute of MIT and Harvard with an Illumina exome capture ( $38 \mathrm{Mb}$ target) and sequenced ( $150 \mathrm{bp}$ paired reads) to cover $>80 \%$ of targets at $20 \mathrm{x}$ and a mean target coverage of 100x. Exome sequencing data was processed through a pipeline based on Picard and mapping done using the BWA aligner to the human genome build 37 (hg19). The variant call sets were uploaded to variant analysis platform seqr (http://seqr.broadinstitute.org). Sanger sequencing was performed in all family members to validate potentially causal variants identified in WES including individuals who were not previously analyzed by WES (OGI842-1650, OGI842-1652). 


\section{Splicing assay}

Variants selected for analysis with the midigene assay were evaluated for possible effects on splicing using both Alamut software (Alamut Visual, http://www.interactive-biosoftware.com/alamut-visual/) and Splice Al neural network (Jaganathan et al., 2019). Two constructs containing GNL3 exons 10-13 including intronic regions and GNL3 with exons 13-15 along with downstream 3' regions, were amplified from patient's genomic DNA (Pfu Ultra II polymerase, Agilent Technologies, Santa Cruz, CA, primers listed in Table S1). The PCR products were cloned into pENTR-TOPO/D (ThermoFisher, Waltham, MA) and verified by Sanger sequencing. Clones carrying essential splice-site mutations were created by sitedirected mutagenesis (QuickChange II Site Directed mutagenesis kit, Agilent Technologies, Santa Cruz, CA) on the wild-type constructs and verified by Sanger sequencing. Clones containing the desired sequences (wild-type, essential splice site and variant to be studied) were sub-cloned into pCSGW2+ vector (Jamshidi et al., 2019) by Gateway cloning using LR clonase (Invitrogen, Carlsbad, CA). pCSGW2+ GNL3 constructs were transfected into HEK293 cells using 3ug of total DNA and Lipofectamine reagent (Invitrogen, Carlsbad, CA) into 6-well plates (Corning, Corning, NY) seeded with $5 \times 10^{\wedge} 5$ cells. Human embryonic kidney cells (HEK293T) were grown on Dulbecco's Modified Eagle's Media (Gibco, Dublin, Ireland) and $10 \%$ fetal bovine serum (Thermo Fisher, Waltham, $\mathrm{MA}$ ) at $37^{\circ} \mathrm{C}$ and $5 \% \mathrm{CO}_{2}$. Total RNA was extracted from cells 72 hours after transfection (RNAeasy mini kit, QIAGEN, Hilden, Germany). cDNA was synthesized with Super Script II reverse transcriptase kit (Invitrogen, Carlsbad, CA) with 500ng RNA input. Finally, PCR amplification using a primer directed towards the plasmid and a second primer specific to the insert containing flanking exons of the splice-site mutations (Supplementary Table S1) was performed followed by visualization by agarose gel electrophoresis and NGS (Illumina, San Diego, CA).

STAR (version 2.5.3a) aligner (Dobin et al., 2012) was used to generate an index of the human genome (GRCh37.75.dna.primary_assembly.fa) and to align the reads for the analysis of splicing patterns from 
amplicon sequencing. Integrative Genomics Viewer (IGV) (Robinson et al., 2011) was used to load the aligned sequences (BAM files) for data visualization with Sashimi plots.

\section{Knockdown in Zebrafish}

This study used an in-house cross of the $A B$ and TL strain (source: ZIRC) for all experiments. Breeding and embryo maintenance were performed in accordance with MEE Zebrafish Core Facility standard procedures and IACUC approved protocols. Embryos were injected at the 1-8 cell stage, where each embryo received $2.3 \mathrm{~nL}$ of either $0.4 \mathrm{mM}$ of the standard control $\mathrm{MO}$ or $0.2 \mathrm{mM}$ of each splice site blocking MO, (Supplementary Table S1). cDNA was extracted from each condition and analyzed via PCR and Sanger sequencing to confirm the effect on splicing. Zebrafish larvae external phenotypes were evaluated at day 5 . Histology was performed by sectioning zebrafish larvae in paraffin blocks and Hematoxylin and Eosin staining ((SERI histology core, MGB).

To confirm morpholino results, CRISPR/Cas9 knockdown was performed targeting pde4dip exons 4 and 13. Zebrafish embryos were collected within 10 minutes of the beginning of breeding to ensure one-cell stage of the embryos. Both sgRNA (targeting exon 4 and 13, Supplementary Table S1) and Cas9 protein (EnGen Spy Cas9, NEB, Ipswich, MA) were co-injected into a cell cytoplasm of one-cell staged embryos. The mosaic F0 fish were kept for 5 days and analyzed functionally as morphant fish. Genomic DNA was extracted from the larvae after each assay and analyzed using NGS to observe cutting efficiency.

\section{Visual motor response and acoustically evoked behavior response}

A combined visual motor response (VMR) and acoustically evoked behavior response (AEBR) assay was used to test the visual function and general motor function, respectively (Emran et al., 2008; Faria et al., 2019; Zeddies and Fay, 2005). In brief, larvae at $5 \mathrm{dpf}$ were tested using the ZebraLab system (ViewPoint Life Sciences, Lyon, France). Larvae with body deformation or other severe external phenotypes were 
excluded. Individual larvae were placed in individual wells of a 96-well plate and placed in the Zebralab system, which is isolated from outside vibration and light. In the AEBR test, larvae were adapted for 10 min before being challenged by three consecutive vibrations ( $200 \mathrm{~Hz}$ for $500 \mathrm{~ms}$ ) with 5 -min intervals under normal light illumination. In the VMR test, larvae were dark-adapted for 40 mins before going through three consecutive trials of light onset and light offset periods that last for 30 minutes each (Emran et al., 2008). The light change (on or off) was abrupt and was not fading. The animal's motor response to the stimuli were recorded using infra-red light and camera. All the functional tests were performed between 10 am and $3 \mathrm{pm}$.

\section{Statistical analysis of zebrafish functional data}

For the combined AEBR and VMR analysis, activity summarization and subsequent statistical analyses were performed using a customized analytical pipeline developed using R software (version 3.5.0, http://www.r-project.org/) building on previous analytical methods (Emran et al., 2008; Liu et al., 2015) . The statistical analysis part of our analytical pipeline script is accessible in a GitHub repository here https://github.com/rongshisong/zebrafish VMR analysis. The differences between conditions and control in the mean activity level at the onset of the acoustic stimulation and during the first second after light change were tested using Tukey HSD with a $p$ value of 0.05 or greater considered significant. All experiments were done with at least $n=96$ fish in each condition. Comparison of gas bladder presence was tested using Fisher's exact test. 


\section{ADDITIONAL INFORMATION}

Data deposition and Access

The causal variant identified in the present study has been deposited to ClinVar

(https://www.ncbi.nih.gov/clinvar/) with accession number SCV001950339.

\section{Ethics Statement}

The study was approved by the institutional review board at the Massachusetts Eye and Ear (MEE), an affiliate of Mass General Brigham (MGB) healthcare system (Human Studies Committee MGB, Boston, MA, USA) and complied with the Health Information Portability and Accessibility Act (HIPAA). All aspects of the project adhered to the tenets of the Declaration of Helsinki. Informed consent was obtained from all individuals on whom genetic testing and further molecular evaluations were performed.

\section{Acknowledgements}

This work was supported by grants from the National Eye Institute [R01EY026904 (KMB/EAP), R01EY012910 (EAP) and P30EY014104 (MEEl core support)], the Foundation Fighting Blindness (EGI-GE1218-0753-UCSD, KMB) and the Curing Kids Foundation. Sequencing and analysis were provided by the Broad Institute of MIT and Harvard Center for Mendelian Genomics (Broad CMG) and was funded by the National Human Genome Research Institute, the National Eye Institute, and the National Heart, Lung and Blood Institute grant UM1HG008900 and in part by National Human Genome Research Institute grant R01 HG009141. The authors would like to thank the patients and their family members for their participation in this study and the Ocular Genomics Institute Genomics Core members for their experimental assistance. The authors would like to thank the Exome Aggregation Consortium, the Genome Aggregation Database (GnomAD) and the groups that provided exome variant data for 
comparison. A full list of contributing groups can be found at http://exac.broadinstitute.org/about and http://gnomad.broadinstitute.org/about.

\section{Author Contributions}

H.S. and A.L. performed experiments and contributed to the writing of the manuscript. S.R. and S.M. provided data analysis. J.L.W. supported zebrafish data analysis and reviewed the manuscript. E.M.P. provided clinical data and reviewed the manuscript. E.A.P. contributed to the experimental design and review the manuscript. K.M.B. guided the experimental design, provided variant analysis and contributed to the writing of the manuscript. 


\section{REFERENCES}

Abu-Safieh, L., Vithana, E.N., Mantel, I., Holder, G.E., Pelosini, L., Bird, A.C., and Bhattacharya, S.S. (2006). A large deletion in the adRP gene PRPF31: evidence that haploinsufficiency is the cause of disease. Molecular vision 12, 384-388.

Arno, G., Agrawal, S.A., Eblimit, A., Bellingham, J., Xu, M., Wang, F., Chakarova, C., Parfitt, D.A., Lane, A., Burgoyne, T., et al. (2016). Mutations in REEP6 Cause Autosomal-Recessive Retinitis Pigmentosa. Am J Hum Genet 99, 1305-1315.

Audo, I., Kohl, S., Leroy, B.P., Munier, F.L., Guillonneau, X., Mohand-Saïd, S., Bujakowska, K., Nandrot, E.F., Lorenz, B., Preising, M., et al. (2009). TRPM1 Is Mutated in Patients with Autosomal-Recessive Complete Congenital Stationary Night Blindness. The American Journal of Human Genetics 85, 720-729. Bainbridge, J.W.B., Smith, A.J., Barker, S.S., Robbie, S., Henderson, R., Balaggan, K., Viswanathan, A., Holder, G.E., Stockman, A., Tyler, N., et al. (2008). Effect of Gene Therapy on Visual Function in Leber's Congenital Amaurosis. New England Journal of Medicine 358, 2231-2239.

Bonnet, C., Riahi, Z., Chantot-Bastaraud, S., Smagghe, L., Letexier, M., Marcaillou, C., Lefèvre, G.M., Hardelin, J.-P., El-Amraoui, A., Singh-Estivalet, A., et al. (2016a). An innovative strategy for the molecular diagnosis of Usher syndrome identifies causal biallelic mutations in $93 \%$ of European patients. European Journal Of Human Genetics 24, 1730.

Bonnet, C., Riahi, Z., Chantot-Bastaraud, S., Smagghe, L., Letexier, M., Marcaillou, C., Lefèvre, G.M., Hardelin, J.P., El-Amraoui, A., Singh-Estivalet, A., et al. (2016b). An innovative strategy for the molecular diagnosis of Usher syndrome identifies causal biallelic mutations in $93 \%$ of European patients. European journal of human genetics : EJHG 24, 1730-1738.

Bujakowska, K.M., Fernandez-Godino, R., Place, E., Consugar, M., Navarro-Gomez, D., White, J., Bedoukian, E.C., Zhu, X., Xie, H.M., Gai, X., et al. (2016). Copy-number variation is an important contributor to the genetic causality of inherited retinal degenerations. Genetics In Medicine 19, 643. Bujakowska, K.M., Zhang, Q., Siemiatkowska, A.M., Liu, Q., Place, E., Falk, M.J., Consugar, M., Lancelot, M.-E., Antonio, A., Lonjou, C., et al. (2015). Mutations in IFT172 cause isolated retinal degeneration and Bardet-Biedl syndrome. Human Molecular Genetics 24, 230-242.

Carss, K.J., Arno, G., Erwood, M., Stephens, J., Sanchis-Juan, A., Hull, S., Megy, K., Grozeva, D., Dewhurst, E., Malka, S., et al. (2017). Comprehensive Rare Variant Analysis via Whole-Genome Sequencing to Determine the Molecular Pathology of Inherited Retinal Disease. The American Journal of Human Genetics 100, 75-90.

Carvalho, C.M.B., and Lupski, J.R. (2016). Mechanisms underlying structural variant formation in genomic disorders. Nature Reviews Genetics 17, 224-238.

Chakarova, C.F., Hims, M.M., Bolz, H., Abu-Safieh, L., Patel, R.J., Papaioannou, M.G., Inglehearn, C.F., Keen, T.J., Willis, C., Moore, A.T., et al. (2002). Mutations in HPRP3, a third member of pre-mRNA splicing factor genes, implicated in autosomal dominant retinitis pigmentosa. Hum Mol Genet 11, 87-92. Consugar, M.B., Navarro-Gomez, D., Place, E.M., Bujakowska, K.M., Sousa, M.E., Fonseca-Kelly, Z.D., Taub, D.G., Janessian, M., Wang, D.Y., Au, E.D., et al. (2014). Panel-based genetic diagnostic testing for inherited eye diseases is highly accurate and reproducible, and more sensitive for variant detection, than exome sequencing. Genetics In Medicine 17, 253.

Dobin, A., Davis, C.A., Schlesinger, F., Drenkow, J., Zaleski, C., Jha, S., Batut, P., Chaisson, M., and Gingeras, T.R. (2012). STAR: ultrafast universal RNA-seq aligner. Bioinformatics 29, 15-21.

Ellingford, J.M., Horn, B., Campbell, C., Arno, G., Barton, S., Tate, C., Bhaskar, S., Sergouniotis, P.I., Taylor, R.L., Carss, K.J., et al. (2018). Assessment of the incorporation of CNV surveillance into gene panel next-generation sequencing testing for inherited retinal diseases. J Med Genet 55, 114-121. Emran, F., Rihel, J., and Dowling, J.E. (2008). A behavioral assay to measure responsiveness of zebrafish to changes in light intensities. J Vis Exp, 923. 
Faria, M., Prats, E., Novoa-Luna, K.A., Bedrossiantz, J., Gómez-Canela, C., Gómez-Oliván, L.M., and Raldúa, D. (2019). Development of a vibrational startle response assay for screening environmental pollutants and drugs impairing predator avoidance. Science of The Total Environment 650, 87-96. Haim, M. (2002). Epidemiology of retinitis pigmentosa in Denmark. Acta ophthalmologica Scandinavica Supplement, 1-34.

Hanany, M., and Sharon, D. (2019). Allele frequency analysis of variants reported to cause autosomal dominant inherited retinal diseases question the involvement of $19 \%$ of genes and $10 \%$ of reported pathogenic variants. Journal of Medical Genetics 56, 536-542.

Ionita-Laza, I., McCallum, K., Xu, B., and Buxbaum, J.D. (2016). A spectral approach integrating functional genomic annotations for coding and noncoding variants. Nat Genet 48, 214-220. Jaganathan, K., Kyriazopoulou Panagiotopoulou, S., McRae, J.F., Darbandi, S.F., Knowles, D., Li, Y.I., Kosmicki, J.A., Arbelaez, J., Cui, W., Schwartz, G.B., et al. (2019). Predicting Splicing from Primary Sequence with Deep Learning. Cell.

Jamshidi, F., Place, E.M., Mehrotra, S., Navarro-Gomez, D., Maher, M., Branham, K.E., Valkanas, E., Cherry, T.J., Lek, M., MacArthur, D., et al. (2019). Contribution of noncoding pathogenic variants to RPGRIP1-mediated inherited retinal degeneration. Genetics in Medicine 21, 694-704.

Karczewski, K.J., Francioli, L.C., Tiao, G., Cummings, B.B., Alföldi, J., Wang, Q., Collins, R.L., Laricchia, K.M., Ganna, A., Birnbaum, D.P., et al. (2019). Variation across 141,456 human exomes and genomes reveals the spectrum of loss-of-function intolerance across human protein-coding genes. bioRxiv, 531210.

Kawashima, M., Kawakita, T., Yoshida, S., Shimmura, S., and Tsubota, K. (2009). Nucleostemin as a possible progenitor marker of corneal epithelial cells. Molecular vision 15, 1162-1168.

Khateb, S., Kowalewski, B., Bedoni, N., Damme, M., Pollack, N., Saada, A., Obolensky, A., Ben-Yosef, T., Gross, M., Dierks, T., et al. (2018). A homozygous founder missense variant in arylsulfatase $G$ abolishes its enzymatic activity causing atypical Usher syndrome in humans. Genetics in medicine : official journal of the American College of Medical Genetics 20, 1004-1012.

Kircher, M., Witten, D.M., Jain, P., O'Roak, B.J., and Cooper, G.M. (2014). A general framework for estimating the relative pathogenicity of human genetic variants. 46, 310-315.

Li, L., Jiao, X., D'Atri, I., Ono, F., Nelson, R., Chan, C.C., Nakaya, N., Ma, Z., Ma, Y., Cai, X., et al. (2018). Mutation in the intracellular chloride channel CLCC1 associated with autosomal recessive retinitis pigmentosa. PLoS genetics 14, e1007504.

Liu, Y., Carmer, R., Zhang, G., Venkatraman, P., Brown, S.A., Pang, C.-P., Zhang, M., Ma, P., and Leung, Y.F. (2015). Statistical Analysis of Zebrafish Locomotor Response. PLOS ONE 10, e0139521.

Lonsdale, J., Thomas, J., Salvatore, M., Phillips, R., Lo, E., Shad, S., Hasz, R., Walters, G., Garcia, F., Young, N., et al. (2013). The Genotype-Tissue Expression (GTEx) project. Nature Genetics 45, 580-585.

MacLaren, R.E., Groppe, M., Barnard, A.R., Cottriall, C.L., Tolmachova, T., Seymour, L., Clark, K.R., During, M.J., Cremers, F.P.M., Black, G.C.M., et al. (2014). Retinal gene therapy in patients with choroideremia: initial findings from a phase $1 / 2$ clinical trial. The Lancet 383, 1129-1137.

Maguire, A.M., Simonelli, F., Pierce, E.A., Pugh, E.N., Mingozzi, F., Bennicelli, J., Banfi, S., Marshall, K.A., Testa, F., Surace, E.M., et al. (2008). Safety and Efficacy of Gene Transfer for Leber's Congenital Amaurosis. New England Journal of Medicine 358, 2240-2248.

Marmor, M.F., Fulton, A.B., Holder, G.E., Miyake, Y., Brigell, M., and Bach, M. (2009). ISCEV Standard for full-field clinical electroretinography (2008 update). Documenta ophthalmologica Advances in ophthalmology 118, 69-77.

McKenna, A., Hanna, M., Banks, E., Sivachenko, A., Cibulskis, K., Kernytsky, A., Garimella, K., Altshuler, D., Gabriel, S., Daly, M., et al. (2010a). The Genome Analysis Toolkit: A MapReduce framework for analyzing next-generation DNA sequencing data. Genome research 20, 1297-1303. 
McKenna, A., Hanna, M., Banks, E., Sivachenko, A., Cibulskis, K., Kernytsky, A., Garimella, K., Altshuler, D., Gabriel, S., Daly, M., et al. (2010b). The Genome Analysis Toolkit: a MapReduce framework for analyzing next-generation DNA sequencing data. Genome research 20, 1297-1303.

McKie, A.B., McHale, J.C., Keen, T.J., Tarttelin, E.E., Goliath, R., van Lith-Verhoeven, J.J.C., Greenberg, J., Ramesar, R.S., Hoyng, C.B., Cremers, F.P.M., et al. (2001). Mutations in the pre-mRNA splicing factor gene PRPC8 in autosomal dominant retinitis pigmentosa (RP13). Human Molecular Genetics 10, 15551562.

Mustapha, M., Chouery, E., Torchard-Pagnez, D., Nouaille, S., Khrais, A., Sayegh, F.N., Mégarbané, A., Loiselet, J., Lathrop, M., Petit, C., et al. (2002). A novel locus for Usher syndrome type I, USH1G, maps to chromosome 17q24-25. Hum Genet 110, 348-350.

Overlack, N., Kilic, D., Bauß, K., Märker, T., Kremer, H., van Wijk, E., and Wolfrum, U. (2011). Direct interaction of the Usher syndrome $1 \mathrm{G}$ protein SANS and myomegalin in the retina. Biochimica et Biophysica Acta (BBA) - Molecular Cell Research 1813, 1883-1892.

Paridaen, J.T.M.L., Janson, E., Utami, K.H., Pereboom, T.C., Essers, P.B., van Rooijen, C., Zivkovic, D., and Maclnnes, A.W. (2011). The nucleolar GTP-binding proteins GnI2 and nucleostemin are required for retinal neurogenesis in developing zebrafish. Developmental Biology 355, 286-301.

Reichel, E., Bruce, A.M., Sandberg, M.A., and Berson, E.L. (1989). An electroretinographic and molecular genetic study of X-linked cone degeneration. American journal of ophthalmology 108, 540-547.

Rivolta, C., McGee, T.L., Rio Frio, T., Jensen, R.V., Berson, E.L., and Dryja, T.P. (2006). Variation in retinitis pigmentosa-11 (PRPF31 or RP11) gene expression between symptomatic and asymptomatic patients with dominant RP11 mutations. Hum Mutat 27, 644-653.

Robinson, J.T., Thorvaldsdóttir, H., Winckler, W., Guttman, M., Lander, E.S., Getz, G., and Mesirov, J.P. (2011). Integrative genomics viewer. Nature Biotechnology 29, 24-26.

Schmitt, S., Aftab, U., Jiang, C., Redenti, S., Klassen, H., Miljan, E., Sinden, J., and Young, M. (2009). Molecular Characterization of Human Retinal Progenitor Cells. Investigative Ophthalmology \& Visual Science 50, 5901-5908.

Schwarz, J.M., Cooper, D.N., Schuelke, M., and Seelow, D. (2014). MutationTaster2: mutation prediction for the deep-sequencing age. Nature Methods 11, 361-362.

Siepel, A., Bejerano, G., Pedersen, J.S., Hinrichs, A.S., Hou, M., Rosenbloom, K., Clawson, H., Spieth, J., Hillier, L.W., Richards, S., et al. (2005). Evolutionarily conserved elements in vertebrate, insect, worm, and yeast genomes. Genome research 15, 1034-1050.

Sullivan, L.S., Bowne, S.J., Seaman, C.R., Blanton, S.H., Lewis, R.A., Heckenlively, J.R., Birch, D.G., Hughbanks-Wheaton, D., and Daiger, S.P. (2006). Genomic Rearrangements of the PRPF31 Gene Account for $2.5 \%$ of Autosomal Dominant Retinitis Pigmentosa. Investigative Ophthalmology \& Visual Science 47, 4579-4588.

Tanackovic, G., Ransijn, A., Thibault, P., Abou Elela, S., Klinck, R., Berson, E.L., Chabot, B., and Rivolta, C. (2011). PRPF mutations are associated with generalized defects in spliceosome formation and pre-mRNA splicing in patients with retinitis pigmentosa. Hum Mol Genet 20, 2116-2130.

Tsai, R.Y., and McKay, R.D. (2002). A nucleolar mechanism controlling cell proliferation in stem cells and cancer cells. Genes Dev 16, 2991-3003.

Van Cauwenbergh, C., Van Schil, K., Cannoodt, R., Bauwens, M., Van Laethem, T., De Jaegere, S., Steyaert, W., Sante, T., Menten, B., Leroy, B.P., et al. (2017). arrEYE: a customized platform for highresolution copy number analysis of coding and noncoding regions of known and candidate retinal dystrophy genes and retinal noncoding RNAs. Genetics in Medicine 19, 457-466.

Van Schil, K., Naessens, S., Van de Sompele, S., Carron, M., Aslanidis, A., Van Cauwenbergh, C., Mayer, A.K., Van Heetvelde, M., Bauwens, M., Verdin, H., et al. (2018). Mapping the genomic landscape of inherited retinal disease genes prioritizes genes prone to coding and noncoding copy-number variations. Genetics in Medicine 20, 202-213. 
Verde, I., Pahlke, G., Salanova, M., Zhang, G., Wang, S., Coletti, D., Onuffer, J., Jin, S.L.C., and Conti, M. (2001). Myomegalin Is a Novel Protein of the Golgi/Centrosome That Interacts with a Cyclic Nucleotide Phosphodiesterase. Journal of Biological Chemistry 276, 11189-11198.

Vithana, E.N., Abu-Safieh, L., Allen, M.J., Carey, A., Papaioannou, M., Chakarova, C., Al-Maghtheh, M., Ebenezer, N.D., Willis, C., Moore, A.T., et al. (2001). A human homolog of yeast pre-mRNA splicing gene, PRP31, underlies autosomal dominant retinitis pigmentosa on chromosome 19q13.4 (RP11). Mol Cell 8, 375-381.

Vithana, E.N., Abu-Safieh, L., Pelosini, L., Winchester, E., Hornan, D., Bird, A.C., Hunt, D.M., Bustin, S.A., and Bhattacharya, S.S. (2003). Expression of PRPF31 mRNA in Patients with Autosomal Dominant Retinitis Pigmentosa: A Molecular Clue for Incomplete Penetrance? Investigative Ophthalmology \& Visual Science 44, 4204-4209.

Wang, Z., Zhang, C., and Qi, R.Z. (2014). A novel myomegalin isoform functions in Golgi microtubule organization and ER-Golgi transport. Journal of Cell Science.

Weil, D., El-Amraoui, A., Masmoudi, S., Mustapha, M., Kikkawa, Y., Lainé, S., Delmaghani, S., Adato, A., Nadifi, S., Zina, Z.B., et al. (2003). Usher syndrome type I G (USH1G) is caused by mutations in the gene encoding SANS, a protein that associates with the USH1C protein, harmonin. Human Molecular Genetics $12,463-471$.

Xu, M., Yamada, T., Sun, Z., Eblimit, A., Lopez, I., Wang, F., Manya, H., Xu, S., Zhao, L., Li, Y., et al. (2016). Mutations in POMGNT1 cause non-syndromic retinitis pigmentosa. Human Molecular Genetics 25, 14791488.

Zampaglione, E., Kinde, B., Place, E.M., Navarro-Gomez, D., Maher, M., Jamshidi, F., Nassiri, S., Mazzone, J.A., Finn, C., Schlegel, D., et al. (2020). Copy-number variation contributes $9 \%$ of pathogenicity in the inherited retinal degenerations. Genetics in Medicine 22, 1079-1087.

Zeddies, D.G., and Fay, R.R. (2005). Development of the acoustically evoked behavioral response in zebrafish to pure tones. Journal of Experimental Biology 208, 1363-1372.

Zeitz, C., Kloeckener-Gruissem, B., Forster, U., Kohl, S., Magyar, I., Wissinger, B., Mátyás, G., Borruat, F.X., Schorderet, D.F., Zrenner, E., et al. (2006). Mutations in CABP4, the Gene Encoding the Ca2+-Binding Protein 4, Cause Autosomal Recessive Night Blindness. The American Journal of Human Genetics 79, 657-667.

Zeitz, C., van Genderen, M., Neidhardt, J., Luhmann, U.F.O., Hoeben, F., Forster, U., Wycisk, K., Mátyás, G.b., Hoyng, C.B., Riemslag, F., et al. (2005). Mutations in GRM6 Cause Autosomal Recessive Congenital Stationary Night Blindness with a Distinctive Scotopic 15- Hz Flicker Electroretinogram. Investigative Ophthalmology \& Visual Science 46, 4328-4335.

Zhao, C., Bellur, D.L., Lu, S., Zhao, F., Grassi, M.A., Bowne, S.J., Sullivan, L.S., Daiger, S.P., Chen, L.J., Pang, C.P., et al. (2009). Autosomal-dominant retinitis pigmentosa caused by a mutation in SNRNP200, a gene required for unwinding of U4/U6 snRNAs. Am J Hum Genet 85, 617-627.

Zhou, Y., Li, S., Huang, L., Yang, Y., Zhang, L., Yang, M., Liu, W., Ramasamy, K., Jiang, Z., Sundaresan, P., et al. (2018). A splicing mutation in aryl hydrocarbon receptor associated with retinitis pigmentosa. Hum Mol Genet 27, 2563-2572. 


\section{FIGURES}

Figure 1. Pedigree and Phenotypic details for Family OGI842. (A) Multigenerational pedigree of OGI842 family. Affected are shown with darkened symbols, proband denoted with arrow, and all subjects that were sequenced have a number designation. (B) Fundus images of the proband (OGI1649) age 33, unaffected mother (OGI1831) 57 years old, and unaffected father (OGI1653) 58 years old.

Figure 2. Investigating variants in GNL3, a candidate gene for IRD. (A) Pedigree analysis confirms segregation of GNL3 with disease, where filled symbols represent affected individuals and empty symbols represent healthy individuals, circles are females and squares are males. (B) NGS analysis of mRNA splicing of the exon10-13 mini gene construct. Read coverage and exon junctions are represented by sashimi plots for the wild type control (red), the c.1187+3A>C variant (blue) and the essential splice site control c.1187+1G>T (green). The corresponding mini gene transcript model with the position of the mutation indicated with a red arrowhead is shown below. Exon 11 skipping (5605 junction reads) and intron 10 retention with partial exon 11 inclusion and exon 12 skipping (4035 reads) are the major effects of the c.1187+3A>C variant. Exon 11 skipping (7523 reads) and exon 11/12 skipping (8059) reads are the major essential in the essential splice site control. Normalizing exon 11 splicing events to adjacent Skipping of exon 11 occurs in 60\% of transcripts (5605/9234 read ratio) as compared to wild type 9242/10914, exon 12 skipping occurs 4035/9234. (C) Sashimi plots generated from the amplicon sequencing on wild type (red), c.1568-8C>A (blue) and essential splice site mutation c.1568-1G>T (green) 
across regions mini gene including exons 13-15. No difference is observed in the splicing pattern between the wild type control and the c.1568-8C>A variant. Essential splice site control, c.1568-1G>T, showed complete intron 14 inclusion.

Figure 3. Investigating PDE4DIP as a candidate gene for IRD. (A) Pedigree analysis confirming segregation of p.Glu1290Lys and p.Ala1535Thr missense variants. (B) Schematic of the PDE4DIP gene and the encoded protein (Myomegalin, PDB: MYOME_HUMAN (Q5VU43)) with mutations indicated (red arrowheads) in exons 26 and 28. (C) Retinal histology of pde4dip morphants at 5 days post fertilization (dpf), showing no observable differences in morphology as compared to controls. (D) VMR assay showing a significant difference in response to light stimuli in pde4dip morphants (red, $\mathrm{n}=144$ ) and control MO (black, $n=143$ ) (Tukey HSD, Light OFF $p=2.73 \times 10^{-13}$, Light ON $p=0.0136$ ). (E) AEBR assay showing decreased response in pde4dip morphants (red) compared to control fish (black) ( $n=144$, Tukey HSD, $p=0.8996$ ) indicating general locomotor abnormalities. (F) Zebrafish analyzed at $5 \mathrm{dpf}$ showing absence of gas bladders in pde4dip morphants. (G) Quantification of the gas bladder presence in pde4dip morphants (red) ( $n=134,54.48 \%$ ) versus control fish (black) ( $n=134,98.51 \%)$ Fisher's exact test $\mathrm{p}<0.0001$.

Figure 4. Validation of PRPF31 duplication. (A) Familial segregation of the c.73_166dup, p.Asp56GlyfsTer33 variant (red bar) on maternal allele (black bar) revealing autosomal dominant inheritance pattern with partial penetrance. Segregation of the paternal wild type allele among siblings with unaffected (white bar) and affected (gray bar). (B) A schematic diagram of the first two coding exons of PRPF31 showing primers used to validate the proposed tandem duplication below. The altered amino acid sequence (p.Asp56GlyfsTer33) of the duplication results in the creation of a stop codon (red octagon). (C) PCR amplification of gDNA from all family members showing the heterozygous duplication (two bands) in all but the father (OGI842-1653). The lower band 335bp is expected for wild type allele, the upper band $429 \mathrm{bp}$ is expected with the inclusion of the $94 \mathrm{bp}$ duplication. (D) Chromatogram for 
Sanger sequencing shows start point for duplication with genomic location hg19 chr19:54621731-

54621824.

Tables 


\begin{tabular}{|c|c|c|c|c|c|c|c|c|c|c|}
\hline $\begin{array}{l}\text { Subject } \\
\text { ID }\end{array}$ & Sex & $\begin{array}{c}\text { Age at } \\
\text { visit } \\
\text { (years) }\end{array}$ & Relationship & Status & $\begin{array}{c}\text { Visual Acuity } \\
\text { (Best } \\
\text { corrected) }\end{array}$ & $\begin{array}{c}\text { Visual Field } \\
\text { (Normal } \geq \\
120)\end{array}$ & Fundus & \multicolumn{3}{|c|}{$\begin{array}{l}\text { Full Field ERG } \\
\text { Normal Values } \\
0.5 \mathrm{~Hz} \text { Amplitude: } 350-700 \mu \mathrm{V} \\
\text { 30Hz Amplitude: } 50-125 \mu \mathrm{V} \\
\text { 30Hz Implicit Time: } 25-32 \mathrm{msec}\end{array}$} \\
\hline $\begin{array}{l}\text { OGI842_ } \\
1649\end{array}$ & $\mathrm{~F}$ & 34 & Proband & $\mathrm{RCD}$ & $\begin{array}{l}\text { OD: } 20 / 30 \\
\text { OS: } 20 / 30\end{array}$ & $\begin{array}{l}\text { OD: } 93.98 \\
\text { OS: } 91.41\end{array}$ & $\begin{array}{l}\text { Waxy pallor of optic disc, } \\
\text { abnormal granularity of the } \\
\text { RPE in the macula OU. } \\
\text { Peripheral bone spicule } \\
\text { pigmentation, as well as } \\
\text { attenuated vessels OU. }\end{array}$ & $\begin{array}{l}\text { 0.5Hz Amp: } \\
\text { 30Hz Amp: } \\
\text { 30Hz Time: }\end{array}$ & $\begin{array}{c}\text { OD: } \\
\text { NA } \\
0.59 \mu \mathrm{V} \\
78 \mathrm{msec}\end{array}$ & $\begin{array}{c}\text { OS: } \\
2.70 \mu \mathrm{V} \\
0.45 \mu \mathrm{V} \\
78 \mathrm{msec}\end{array}$ \\
\hline $\begin{array}{l}\text { OGI842_ } \\
1831\end{array}$ & $\mathrm{~F}$ & 57 & Mother & unaffected & $\begin{array}{l}\text { OD:20/25+3 } \\
\text { OS: } 20 / 30\end{array}$ & Full & $\begin{array}{l}\text { Optic disc, macula, vessels and } \\
\text { periphery all normal. Minimal } \\
\text { cortical lens opacities indicating } \\
\text { mild cataracts. No evidence of } \\
\text { RCD }\end{array}$ & $\begin{array}{l}\text { 0.5Hz Amp: } \\
\text { 30Hz Amp: } \\
\text { 30Hz Time: }\end{array}$ & $\begin{array}{c}\text { OD: } \\
494 \mu \mathrm{V} \\
71 \mu \mathrm{V} \\
31 \mathrm{msec}\end{array}$ & $\begin{array}{c}\text { OS: } \\
\text { no data } \\
65 \mu \mathrm{V} \\
33 \mathrm{msec}\end{array}$ \\
\hline $\begin{array}{l}\text { OGI842_ } \\
1653\end{array}$ & $M$ & 58 & Father & unaffected & $\begin{array}{l}\text { OD:20/20 } \\
\text { OS: } 20 / 200\end{array}$ & $\begin{array}{l}\text { Full } \\
\text { OD: } 100 \\
\text { OS: } 114\end{array}$ & $\begin{array}{l}\text { Optic disc, macula and vessels } \\
\text { are normal. Nasal fundus } \\
\text { slightly tigroid in periphery. No } \\
\text { evidence of RCD }\end{array}$ & $\begin{array}{l}\text { 0.5Hz Amp: } \\
\text { 30Hz Amp: } \\
\text { 30Hz Time: }\end{array}$ & $\begin{array}{c}\text { OD: } \\
317.6 \mathrm{uV} \\
41.2 \mathrm{uV} \\
31.5 \mathrm{msec}\end{array}$ & $\begin{array}{c}\text { OS: } \\
470.6 \mu \mathrm{V} \\
47.1 \mu \mathrm{V} \\
\text { NA }\end{array}$ \\
\hline
\end{tabular}

ERG: Electroretinogram; RCD: Rod-Cone Dystrophy; OU: both eyes, OD: right eye, OS: left eye. 
Table 2. Variants identified in Whole exome sequencing

\begin{tabular}{|c|c|c|c|c|c|c|c|c|c|c|}
\hline Gene & $\begin{array}{l}\text { cDNA } \\
\text { change }\end{array}$ & Consequence & CADD & $\begin{array}{c}\text { Mutation } \\
\text { Taster }\end{array}$ & $\begin{array}{c}\text { Splice } \\
\text { Al }\end{array}$ & gnomAD & $\begin{array}{c}\text { Phast } \mathrm{E} \\
\text { Con }\end{array}$ & Eigen & ClinVar & ACMG \\
\hline GNL3 & c. $1187+3 A>C$ & $\begin{array}{c}\text { Exon } \\
\text { skipping }\end{array}$ & 14 & $\begin{array}{l}\text { Disease } \\
\text { causing }\end{array}$ & 0.75 & Absent & 0.999 & 18 & NR & $\begin{array}{c}\text { LP, Likely } \\
\text { pathogenic } \\
\text { PVS1, PS3, PM2, } \\
\text { PP1, PP3, BP5 }\end{array}$ \\
\hline GNL3 & c. $1568-8 C>A$ & NA & 7.4 & $\begin{array}{l}\text { Disease } \\
\text { causing }\end{array}$ & 0.15 & Absent & 0.001 & 8.1 & NR & $\begin{array}{c}\text { VUS, Uncertain } \\
\text { significance, PM2, } \\
\text { PM3, PP3, PP4, BS3, } \\
\text { BP5 }\end{array}$ \\
\hline PDE4DIP & c.3868G >A & p.Glu1290Lys & 32 & $\begin{array}{l}\text { Disease } \\
\text { causing }\end{array}$ & 0.0 & $1.32 \times 10^{-5}$ & 1.00 & 6.9 & NR & $\begin{array}{c}\text { LB, Likely benign, } \\
\text { PM2, PP3, PP4, BS3, } \\
\text { BP5 }\end{array}$ \\
\hline PDE4DIP & c. $4603 \mathrm{G}>\mathrm{A}$ & p.Ala1535Thr & 23 & $\begin{array}{c}\text { Poly- } \\
\text { morphism }\end{array}$ & 0.0 & $\begin{array}{c}3.281 \times 10^{-} \\
4\end{array}$ & 0.773 & 1.0 & $N R$ & $\begin{array}{c}\text { LB, Likely benign, } \\
\text { PM2, PP3, PP4, BS3, } \\
\text { BP5 }\end{array}$ \\
\hline PRPF31 & c.73_166dup & $\begin{array}{c}\text { p.Asp56Glyfs } \\
\text { Ter33 }\end{array}$ & NA & $\begin{array}{l}\text { Disease } \\
\text { causing }\end{array}$ & NA & Absent* & NA & NA & LP & $\begin{array}{c}\text { P, Pathogenic } \\
\text { PVS1, PM2, PP1, } \\
\text { PP3, PP4 }\end{array}$ \\
\hline
\end{tabular}

CADD, Combined Annotation Dependent Depletion; gnomAD, Genome Aggregation Database; PhastCon, PHylogenetic Analysis with Space/Time models; ACMG, American College of Medical Genetics and Genomics; NR, not reported; Absent* from both gnomAD and gnomAD-SV. 
Family OGI842

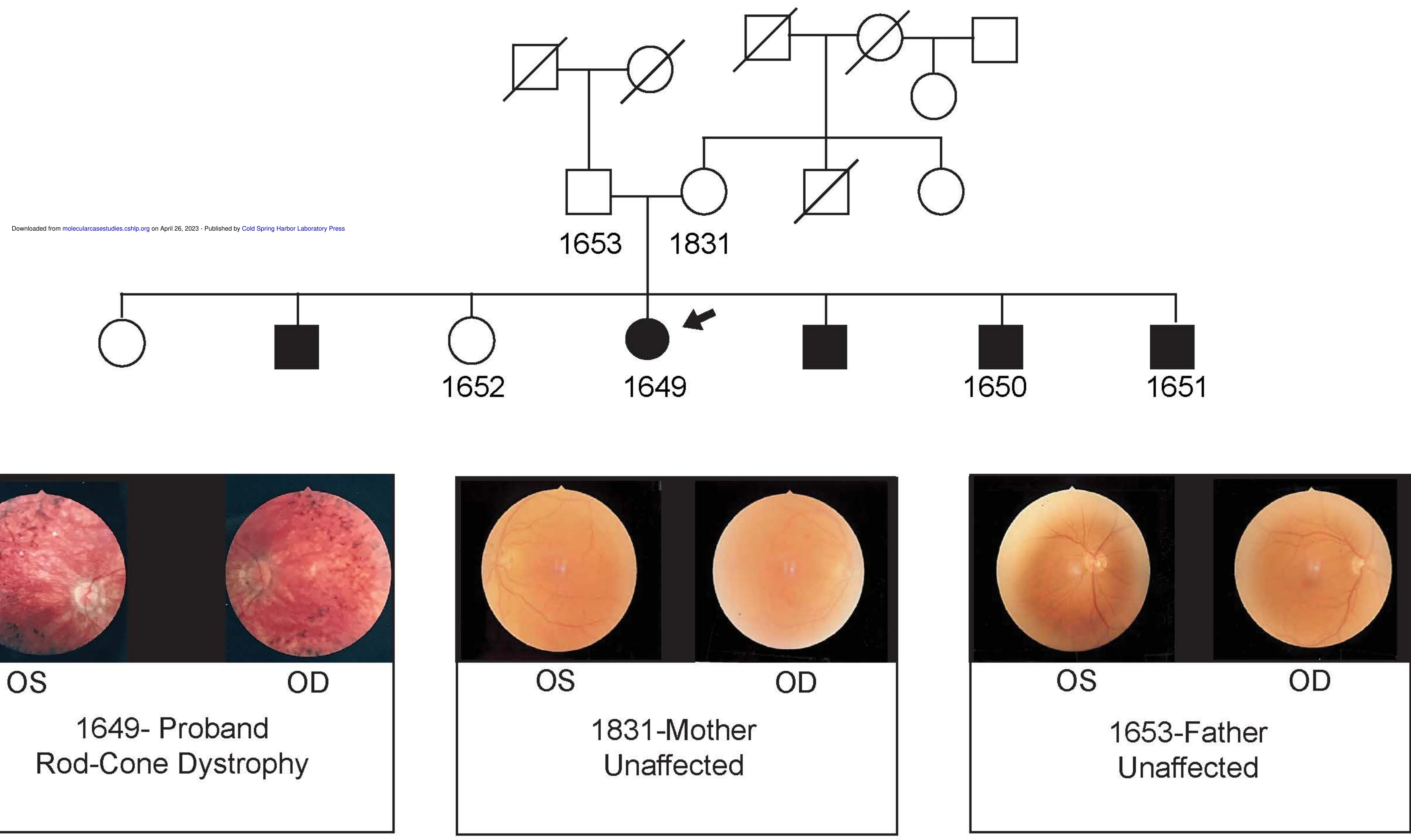




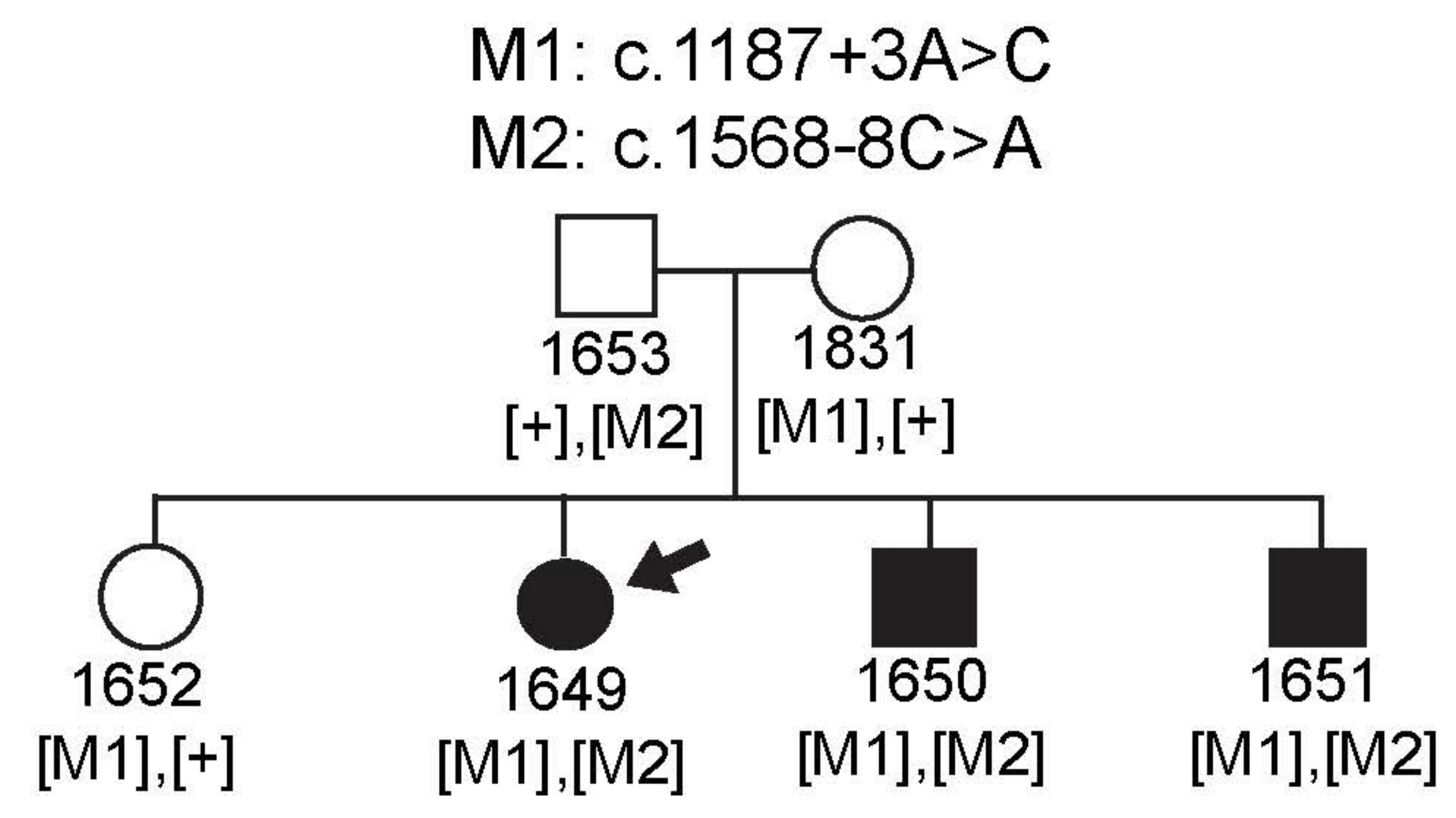

B
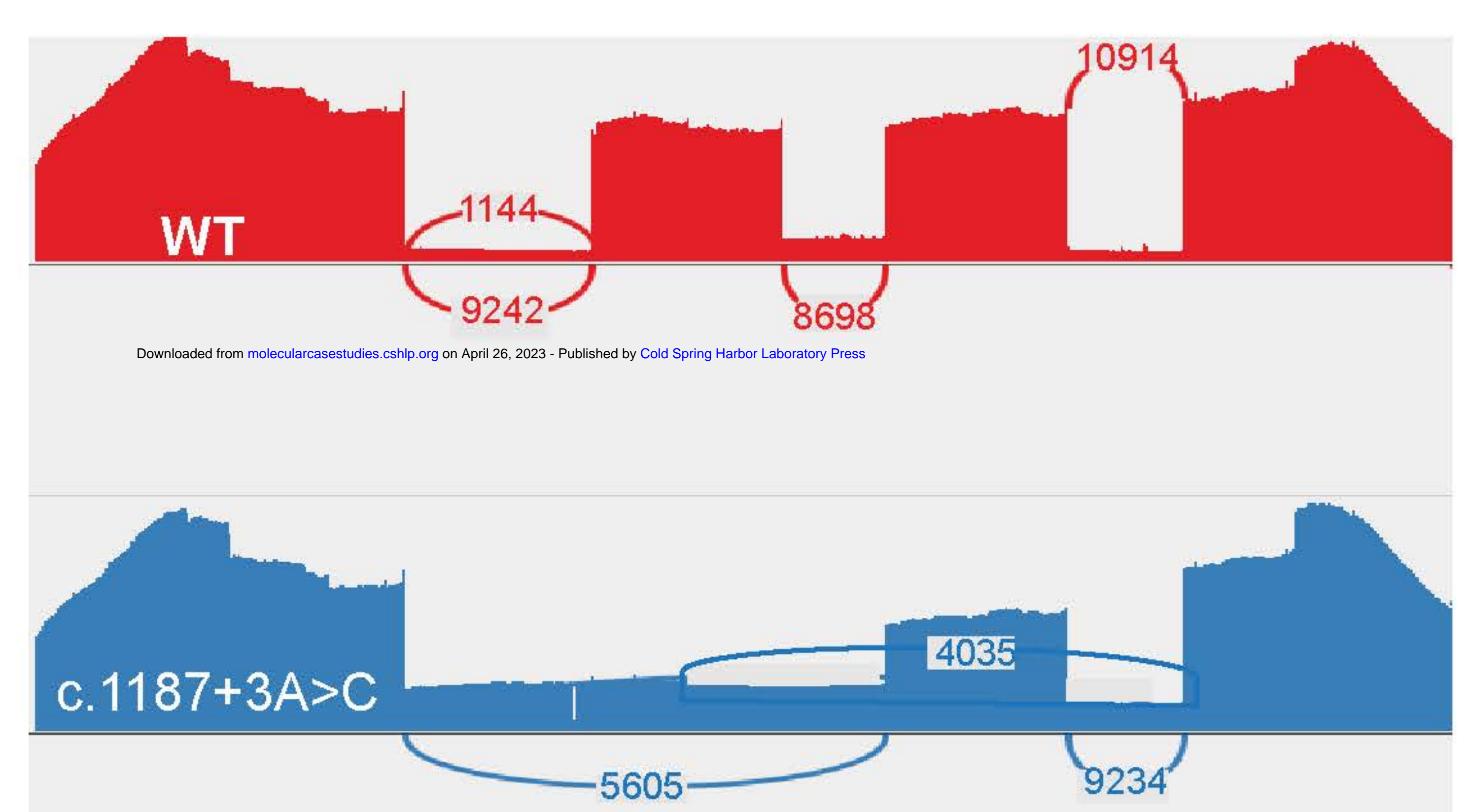

c. $1187+1 \mathrm{G}>\mathrm{T}$

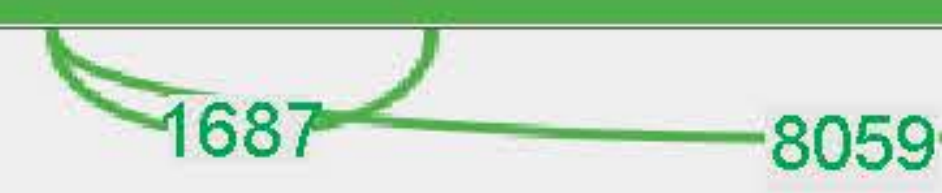

10

\section{1}

c. $1187+3 A>C$
C
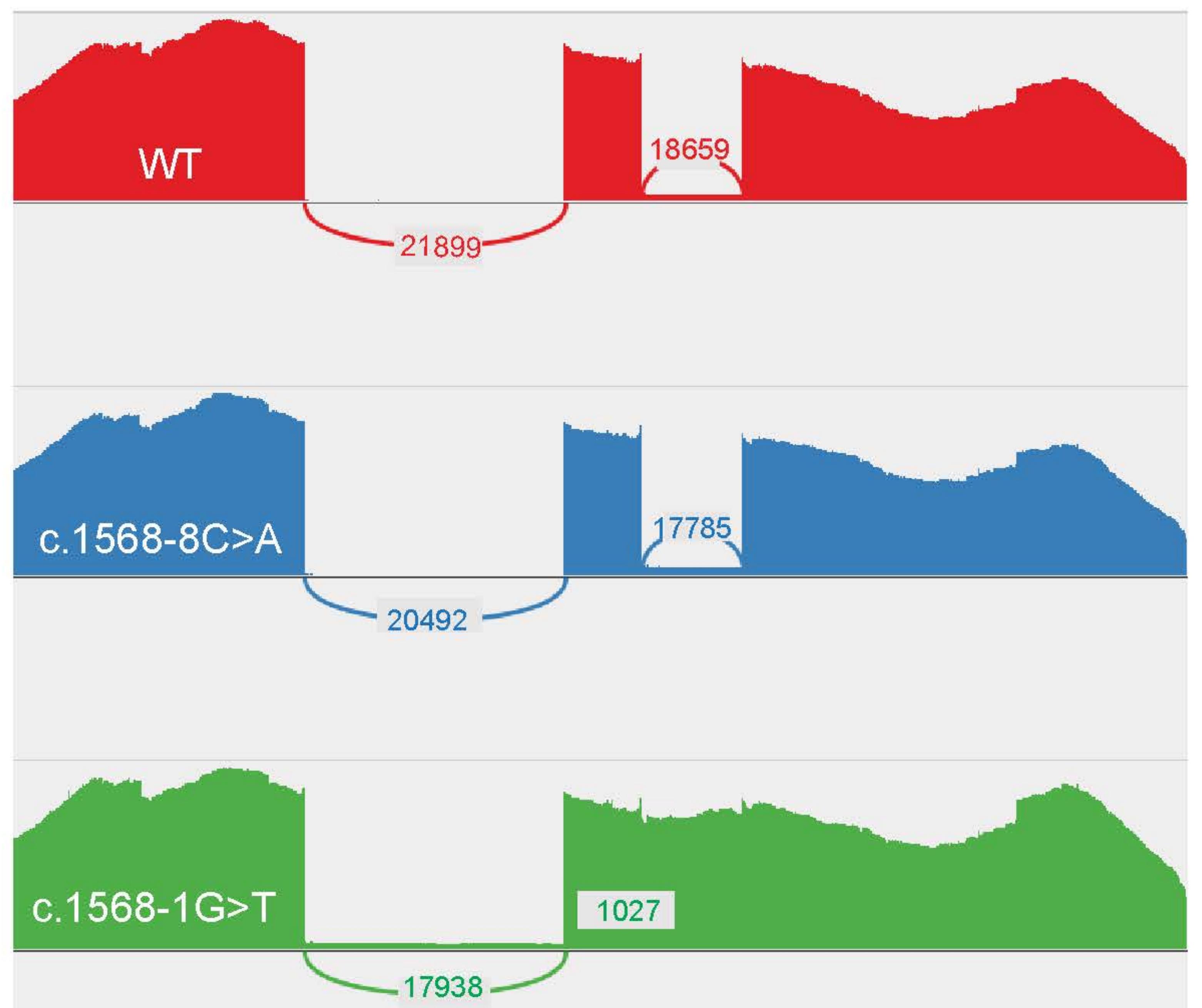

13

14

c. $1586-8 C>A$
15 
A PDE4DIP

Family OGI842

M3: c.3868G>A, p.Glu1290Lys

M4: c.4603G>A, p.Ala1535Thr
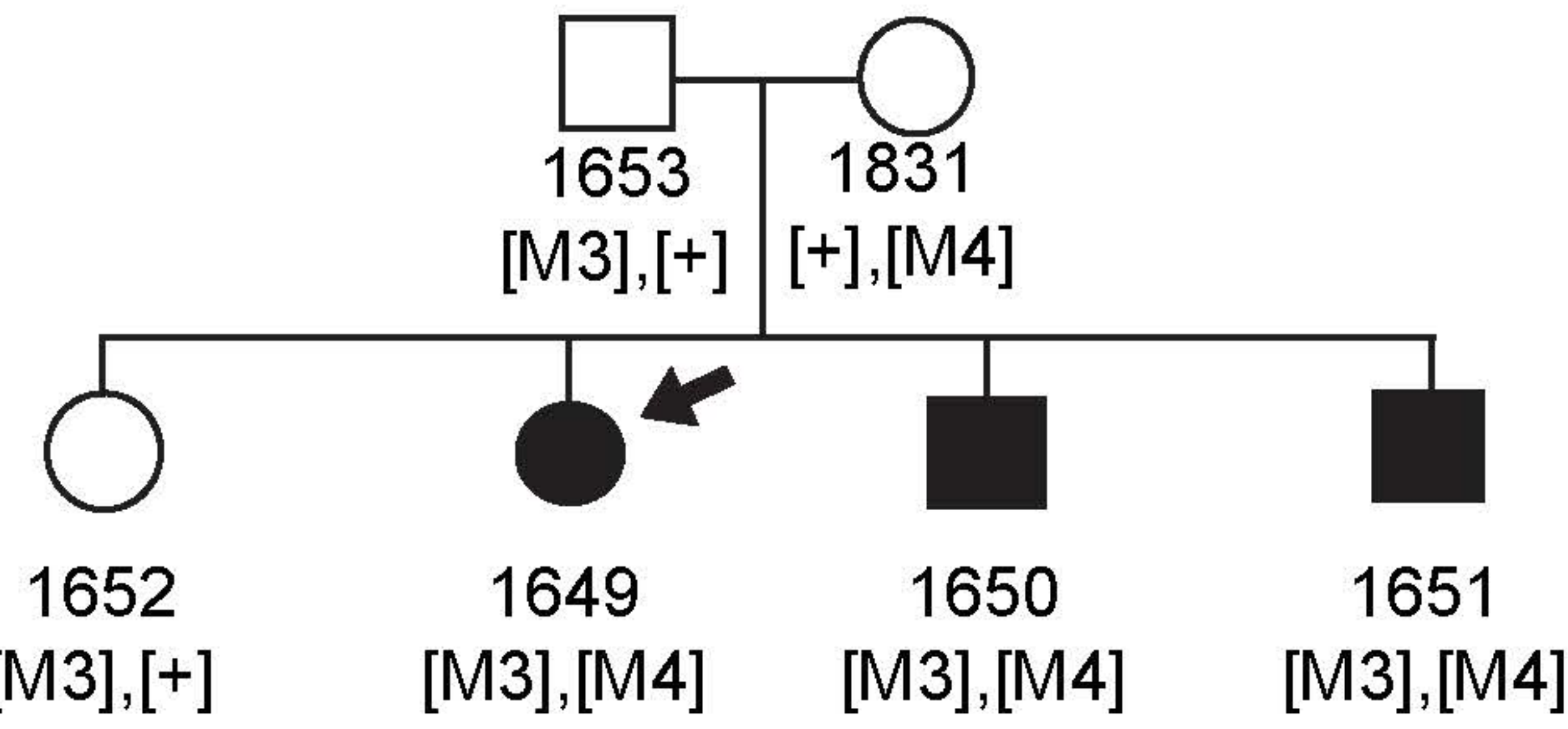

C

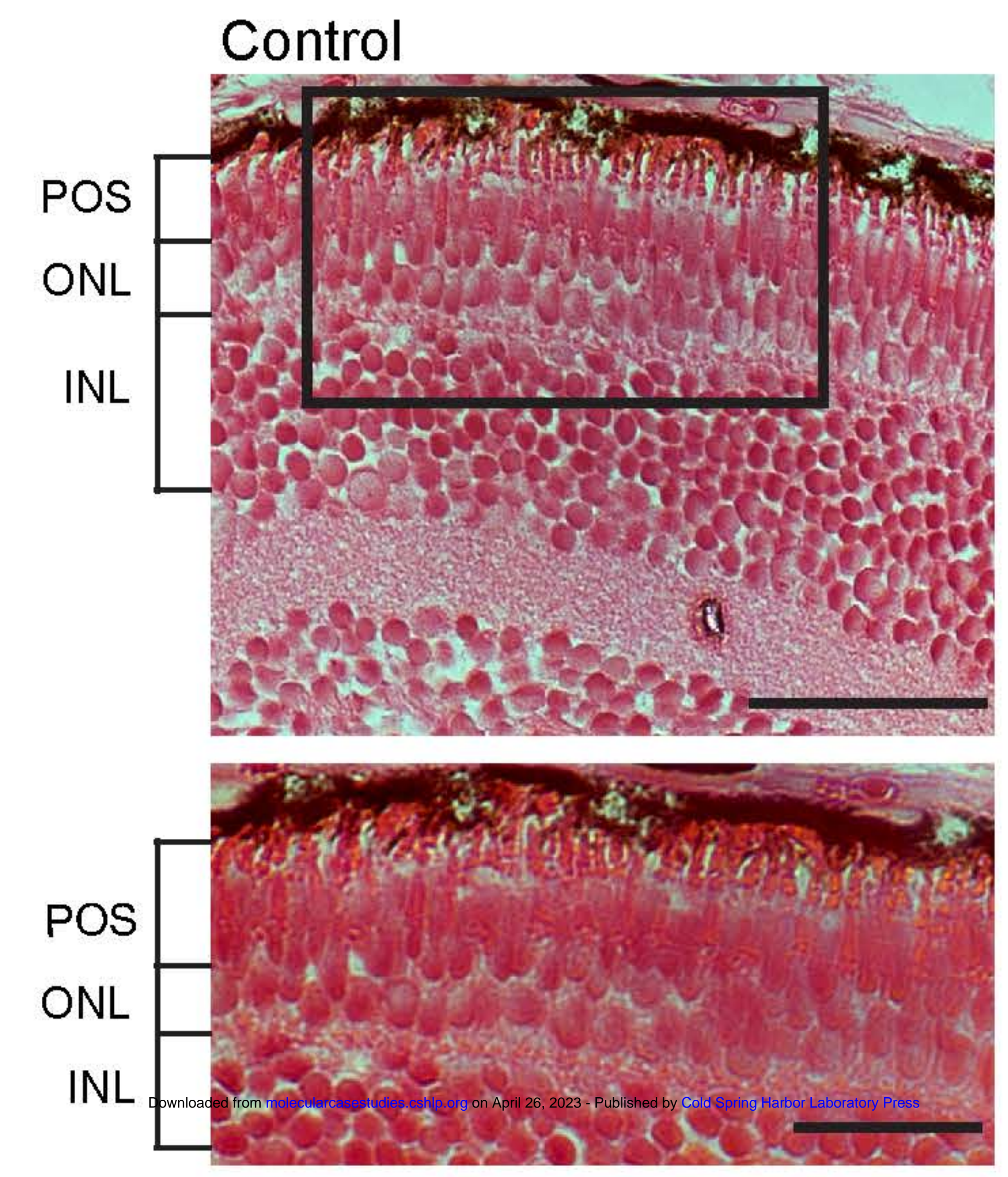

pde4dip morphants
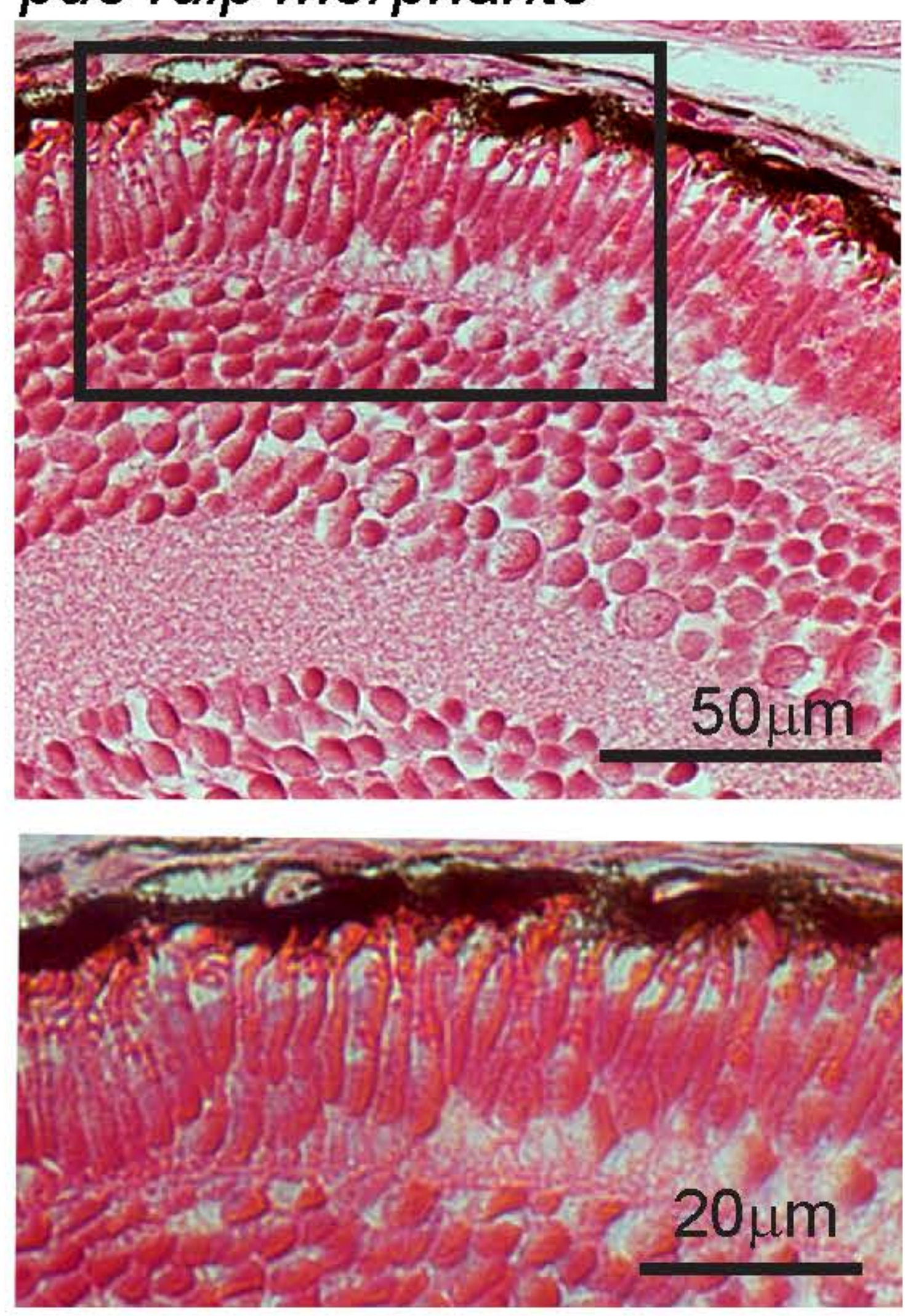

$\mathbf{F}$

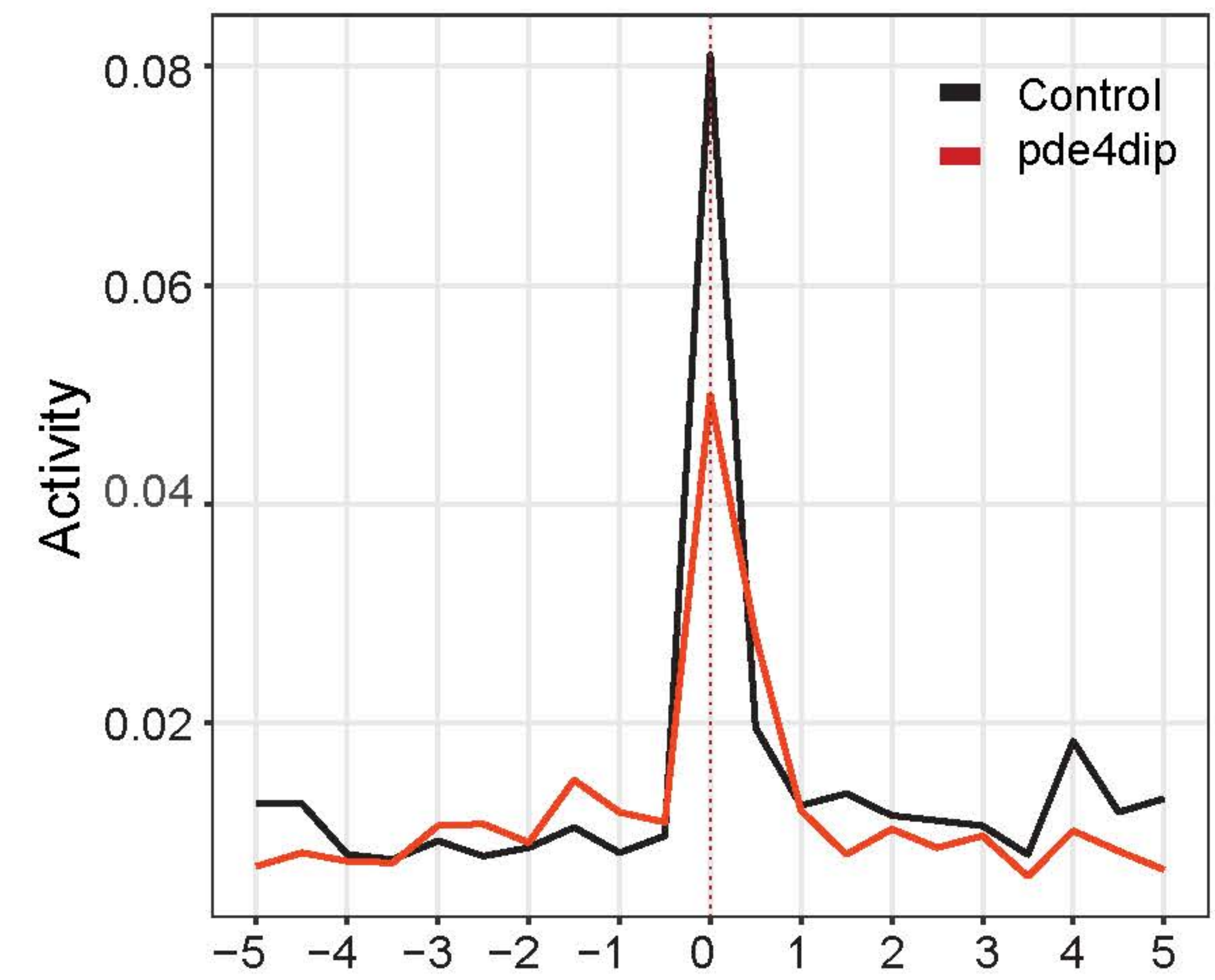

Time centered at acoustic stimulus (seconds)
B

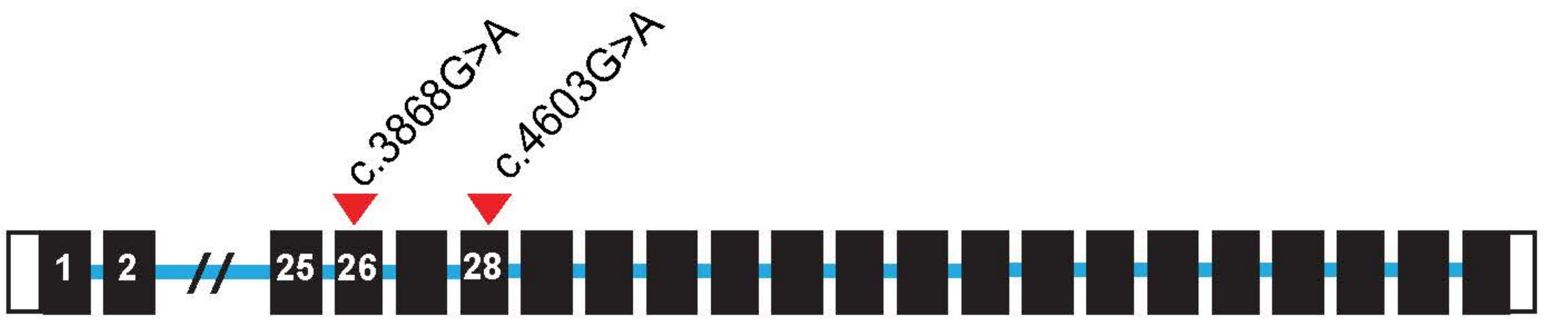

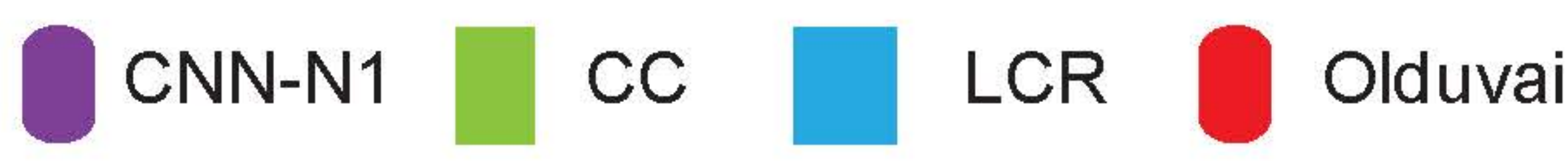

D

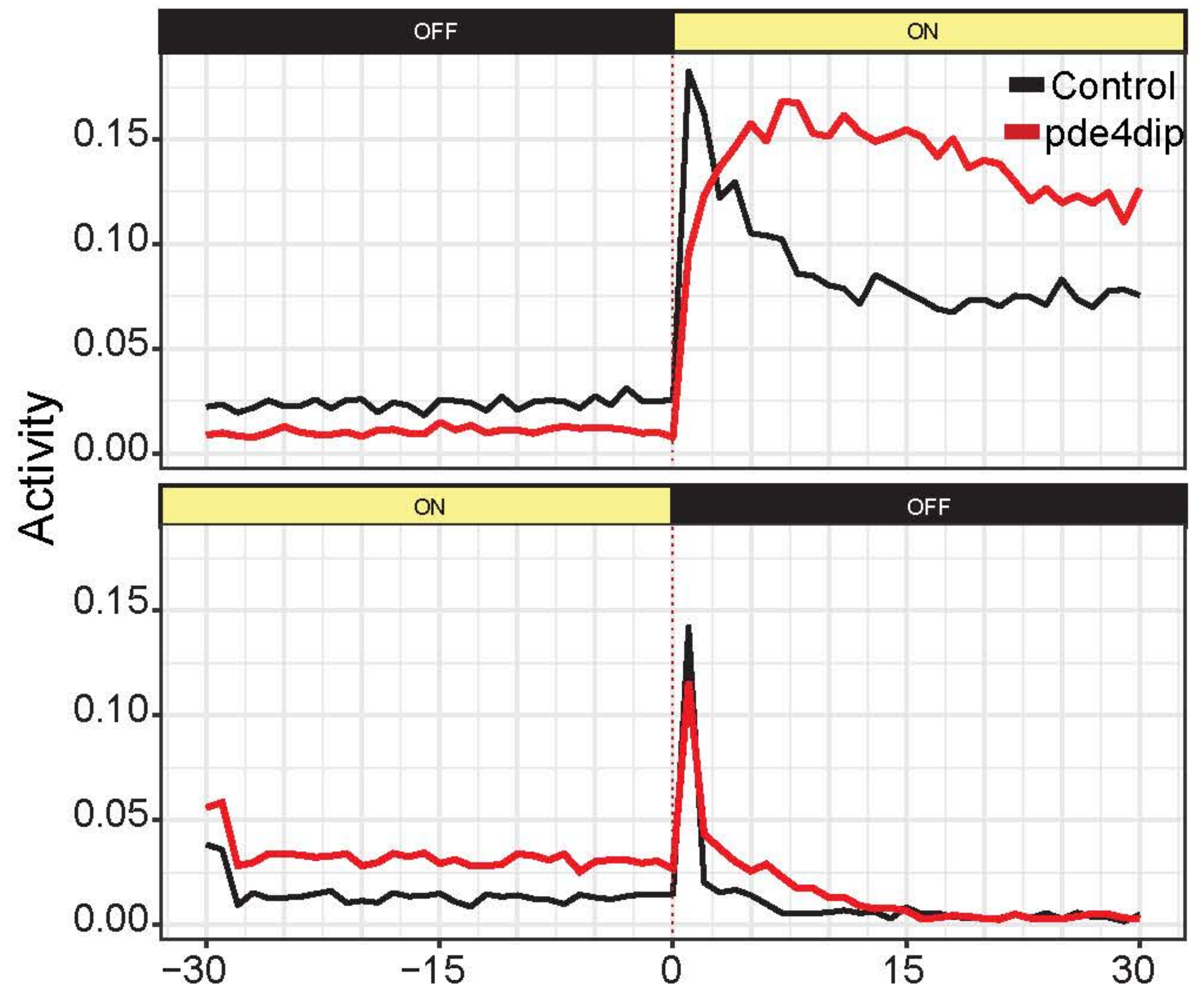

Time centered at light-switching point (seconds)

G

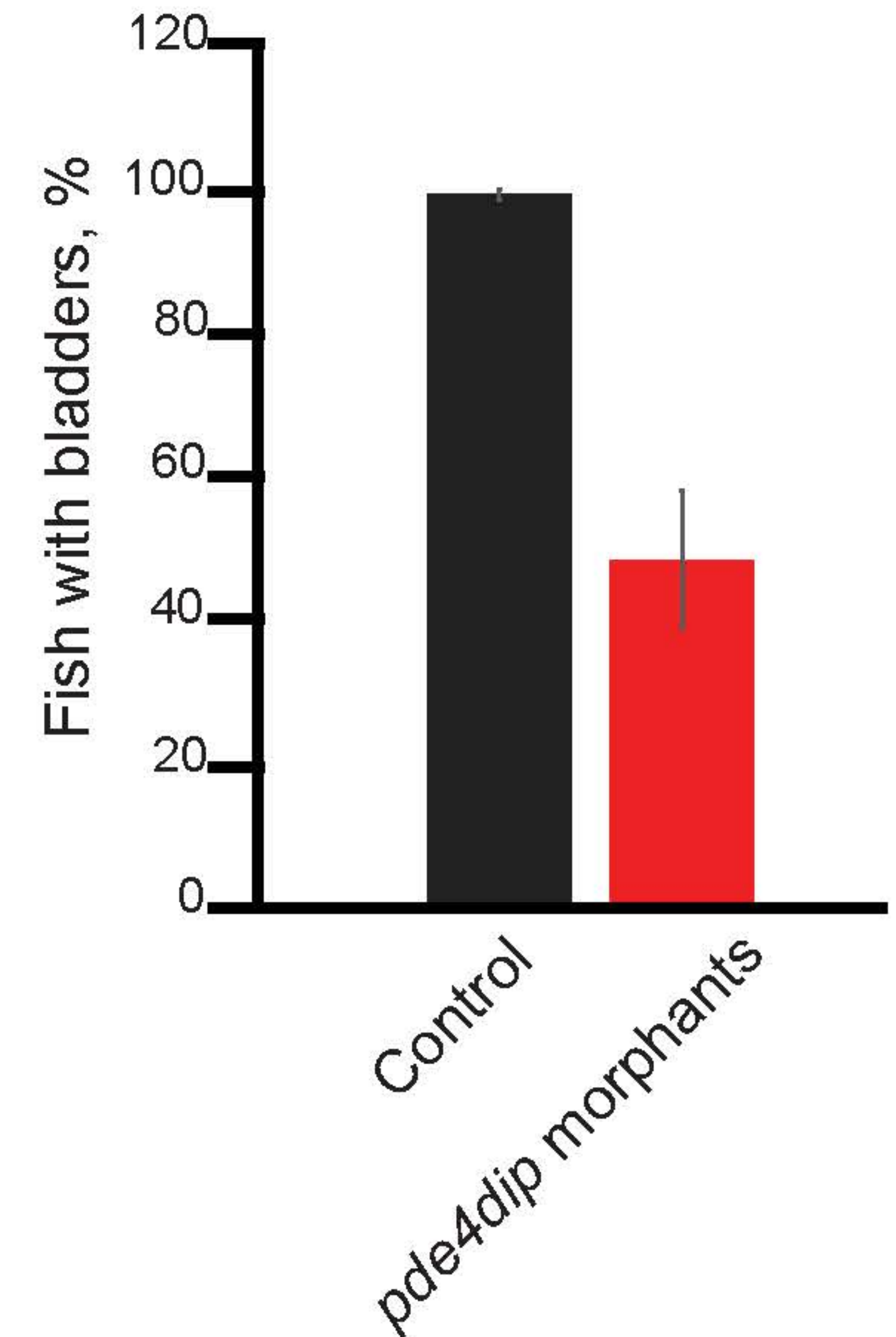




\section{A PRPF31}

M5: c.73_166dup, p.Asp56GlyfsTer33
Family OGI842

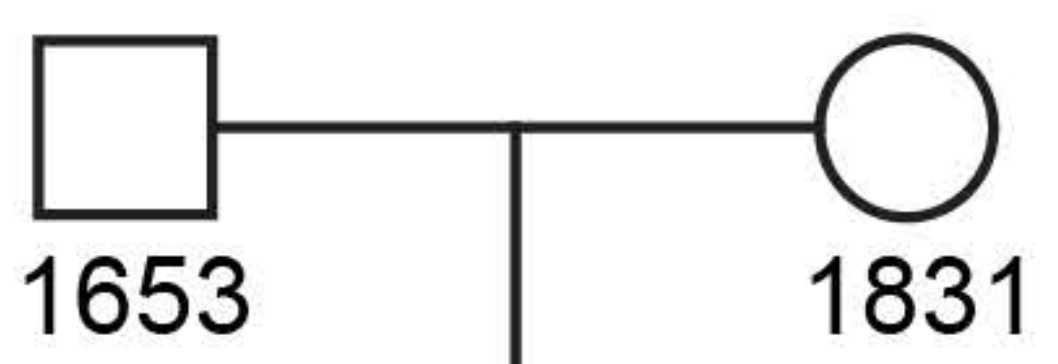

$\mathrm{A}$
+
$\mathrm{A}$
$\mathrm{CG}$
$\mathrm{T}$\|\|$\left[\begin{array}{lll}\mathrm{C} & \mathrm{C} \\ + & + & \mathrm{C} \\ \mathrm{G} & \mathrm{G} & \mathrm{M} 5 \\ \mathrm{C} & \mathrm{C} \\ \mathrm{C} & \mathrm{C}\end{array} \| \begin{array}{l}\mathrm{G} \\ \mathrm{C}\end{array}\right.$

chr19: 54618999 C>A

chr19: 54621731 M5: c73_166dup chr19: $54631381 \mathrm{G}>\mathrm{A}$ rs45513391 chr19: $54631885 \mathrm{C}>\mathrm{CG}$ chr19: 54634830 C > T rs62144168

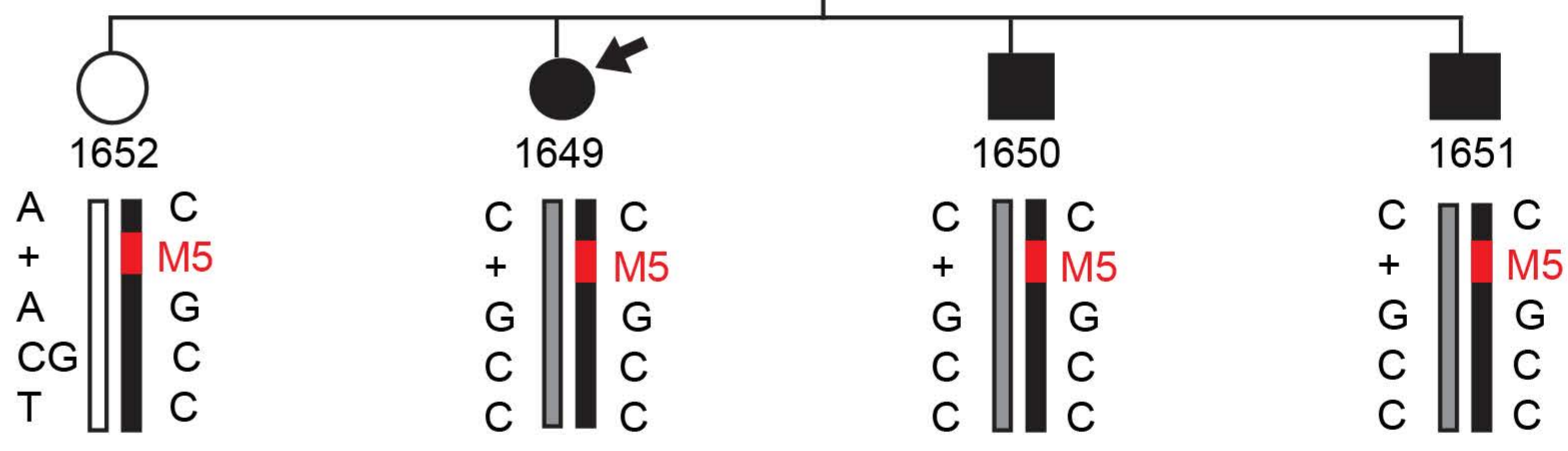

B PCR

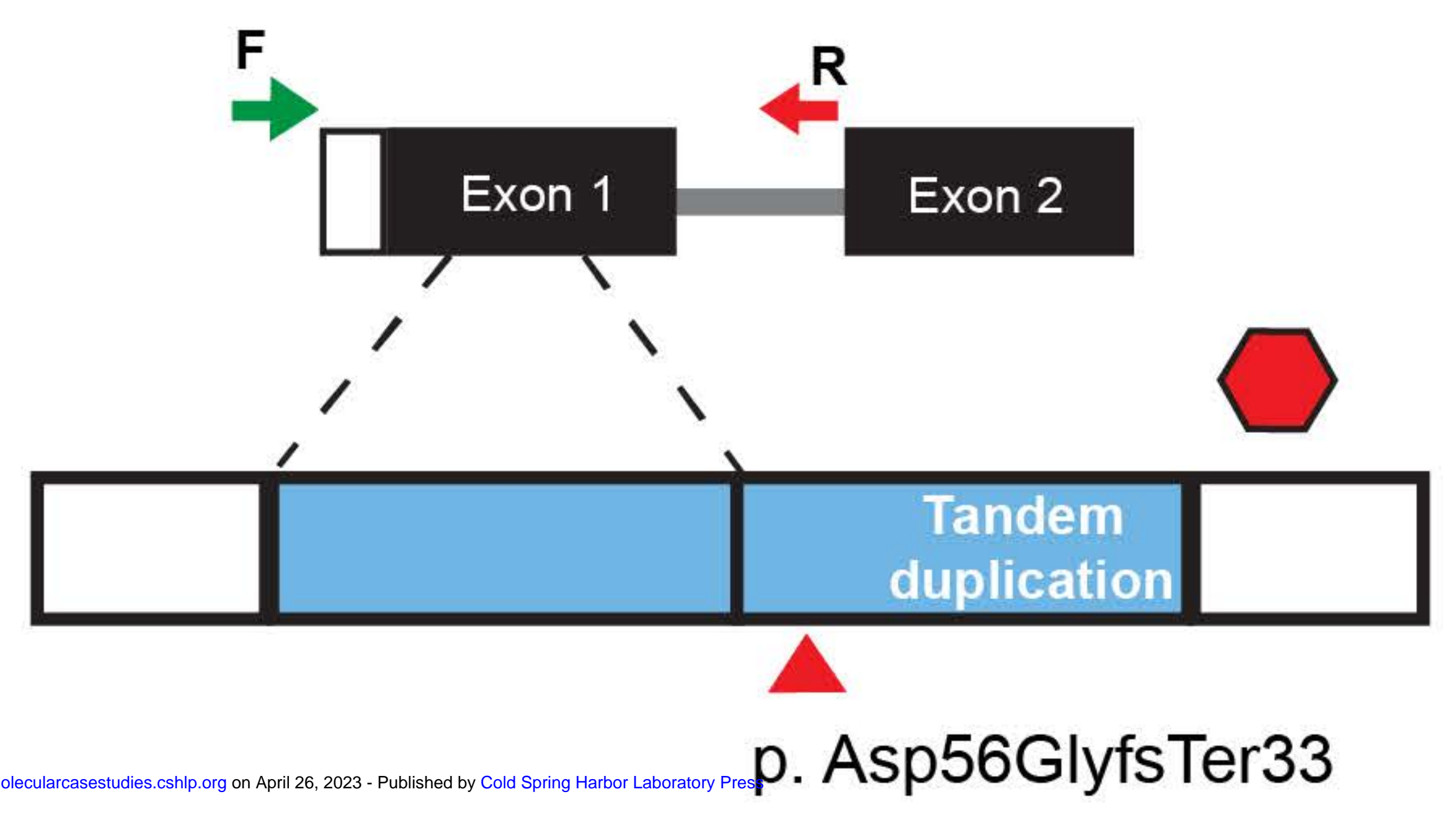

GGSYGEEEEEPAIEDVQEETQLDLSGDSVKTIAX
C

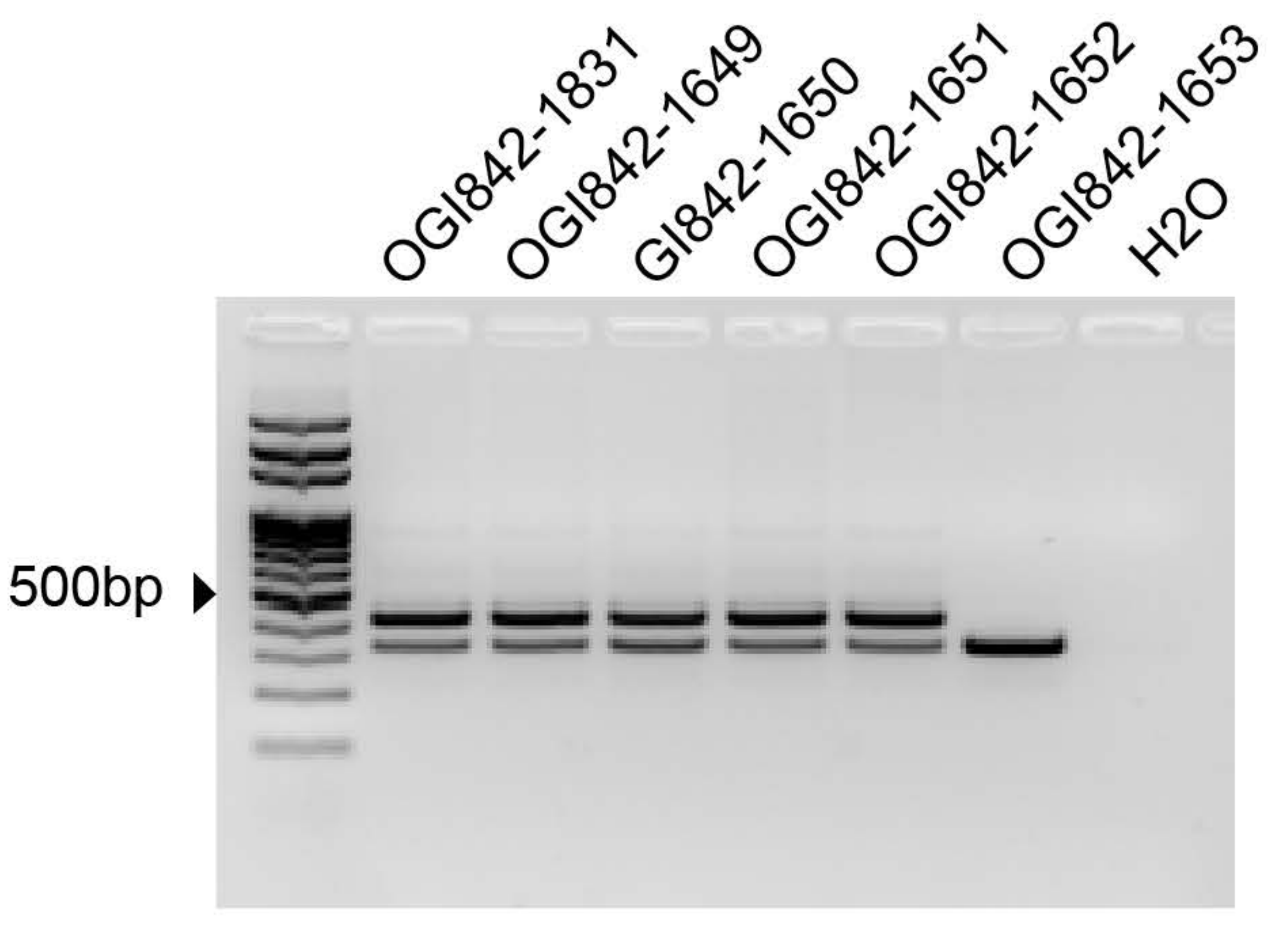

D Sanger sequencing

94bp tandem duplication, chr 19: 54621731-54621824

Duplication start 


\section{COLD SPRING HARBOR Molecular Case Studies}

\section{A Hidden Structural Variation in a Known IRD Gene: A Cautionary Tale of Two New Disease Candidate Genes}

Hilary A Scott, Anna Larson, Shi Song Rong, et al.

Cold Spring Harb Mol Case Stud published online November 2, 2021

Access the most recent version at doi:10.1101/mcs.a006131

\section{Supplementary http://molecularcasestudies.cshlp.org/content/suppl/2021/11/02/mcs.a006131.D Material C1}

Published online November 2, 2021 in advance of the full issue.

Accepted Peer-reviewed and accepted for publication but not copyedited or typeset; accepted Manuscript manuscript is likely to differ from the final, published version. Published onlineNovember 2, 2021 in advance of the full issue.

Creative This article is distributed under the terms of the

Commons http://creativecommons.org/licenses/by-nc/4.0/, which permits reuse and License redistribution, except for commercial purposes, provided that the original author and source are credited.

Email Alerting Receive free email alerts when new articles cite this article - sign up in the box at the Service top right corner of the article or click here. 